\title{
Combination of phospholipase C $\varepsilon$ knockdown with GANT61 sensitizes castration-resistant prostate cancer cells to enzalutamide by suppressing the androgen receptor signaling pathway
}

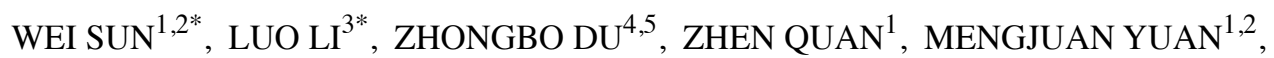 \\ HONGLIN CHENG $^{1}$, YINGYING GAO ${ }^{3,6}$, CHUNLI LUO ${ }^{3}$ and XIAOHOU WU ${ }^{1}$ \\ ${ }^{1}$ Department of Urology, The First Affiliated Hospital, Chongqing Medical University, Chongqing 400016; \\ ${ }^{2}$ Department of Urology, Fuling Center Hospital of Chongqing City, Chongqing 408000; \\ ${ }^{3}$ Key Laboratory of Laboratory Medical Diagnostics, Ministry of Education, Department of Laboratory Medicine, \\ Chongqing Medical University, Chongqing 400016; ${ }^{4}$ Department of Urology, Affiliated Hospital of \\ North Sichuan Medical College; ${ }^{5}$ North Sichuan Medical College, Nanchong, Sichuan 637000; \\ ${ }^{6}$ Department of Laboratory Diagnosis, Jiamusi University, Jiamusi, Heilongjiang 154007, P.R. China
}

Received October 8, 2018; Accepted March 4, 2019

DOI: 10.3892/or.2019.7054

\begin{abstract}
Castration-resistant prostate cancer (CRPC) is a major challenge in the treatment of prostate cancer $(\mathrm{PCa})$. Phospholipase $\mathrm{C} \varepsilon$ (PLCe), an oncogene, has been found to be involved in the carcinogenesis, tumor proliferation and migration of several types of cancer. The effects, however, of PLCE on CRPC remains unclear. In the present study, the expression of PLCe and glioma-associated homolog (Gli)-1/Gli-2 in benign prostatic hyperplasia (BPH), PCa and CRPC tissues and cells was investigated, and the correlations between PLCE and Gli-1/Gli-2 in CRPC tissues and cell lines were further explored. In addition, the effect of PLCE on cell proliferation and invasion was assessed in CRPC cell lines, and the sensitivity of EN-R and 22RV1 cells to enzalutamide following the downregulation of PLC $\varepsilon$ expression was determined using lentivirus-mediated ShPLC $\varepsilon$ and/or treatment with specific Gli inhibitor GANT61. It was found that the PLCe expression was excessively upregulated in the majority of CRPC tissues, and PLCe positivity was linked to poor progression-free survival (PFS) and overall survival (OS) in patients with PCa. Furthermore, PLC $\varepsilon$ knockdown significantly suppressed CRPC cell proliferation and invasion. Of note, it was found that
\end{abstract}

Correspondence to: Professor Xiaohou Wu or Dr Wei Sun, Department of Urology, The First Affiliated Hospital, Chongqing Medical University, 1 Yixueyuan Road, Chongqing 400016, P.R. China

E-mail: 25241970@qq.com

E-mail: sunwei8394@163.com

*Contributed equally

Key words: castration-resistant prostate cancer, phospholipase CE, Hedgehog signaling, enzalutamide, GANT61, androgen receptor
PLCE knockdown increased the sensitivity of CRPC cells to enzalutamide in vitro by suppressing androgen receptor (AR) activities via the non-canonical Hedgehog/Gli-2 and p-STAT3 signaling pathways. PLCE knockdown was shown to increase the sensitivity of CRPC cell xenografts to enzalutamide in vivo. Finally, the combination of PLCe knockdown with GANT61 significantly sensitized CRPC cells to enzalutamide. Collectively, the results of the present study suggest that PLCE is a potential therapeutic target for CRPC.

\section{Introduction}

Prostate cancer (PCa) is one of the most common malignant tumors of the male urinary system. Statistical analysis has shown that more than 250,000 men succumb to $\mathrm{PCa}$ worldwide, with at least 900,000 new cases each year (1). In China, the incidence and mortality rates of $\mathrm{PCa}$ are annually increasing and tend to affect younger individuals $(2,3)$. Current treatments for PCa include surgical treatment and androgen deprivation therapy (ADT). However, almost all patients become resistant to long-term treatment, developing castration-resistant PCa (CRPC). CRPC is characterized by the increased activation and/or overexpression of androgen receptor (AR), resulting in the transcription of downstream target genes and tumor progression, despite castrate levels of androgen in the patient (4). Only a limited number of drugs can be effective once the tumor progresses to CRPC. Fortunately, enzalutamide is one of them. Enzalutamide is an AR inhibitor that competitively inhibits the binding of androgens to receptors and hinders the nuclear transport of the AR and the interaction of the receptor with DNA. Although enzalutamide has achieved some good clinical results (5-7), the subsequent drug resistance remains a challenge. It is therefore, necessary to determine the mechanism of CRPC resistance to enzalutamide.

Phospholipase $\mathrm{C} \varepsilon$ (PLCE), a multifunctional signaling protein harboring both PLC and guanine nucleotide 
exchange factor activities, was discovered by Song et al in $2001(8,9)$. As a member of the human phospholipase C family, PLC $\varepsilon$ has been identified as an oncogene involved in carcinogenesis, tumor proliferation and migration $(10,11)$. Our previous study showed that PLCE knockdown inhibited PCa cell proliferation via the PTEN/AKT signaling pathway (12). Furthermore, it was found that PLC $\varepsilon$ inhibited the biological behavior of $\mathrm{PCa}$ cells by downregulating AR (13). Nonetheless, the role of PLCE in CRPC cells remains unknown. The aim of the present study was to explore the effect of PLC $\varepsilon$ on the proliferation of CRPC cells and determine whether PLC $\varepsilon$ can sensitize CRPC cells to the AR axis inhibitor, enzalutamide.

The Hedgehog $(\mathrm{Hh})$ signaling pathway plays a critical role in the development and homeostasis of many organs and tissues. It consists of the Hh ligand (Shh, Ihh and Dhh), two transmembrane receptor complexes [patched (Ptch) and smoothened (Smo)], and the downstream transcription factor glioma-associated homolog (Gli) family (Gli-1, Gli-2 and Gli-3). Gli-1 and Gli-2 are responsible for most transcriptional activator functions, whereas Gli-3 mainly acts as a repressor. Gli-1 is a direct transcriptional target of the Hh signaling and a marker for pathway activity (14). Vismodegib and cyclopamine are classic Hh signaling pathway inhibitors. Vismodegib blocks the biological activity of the Hh pathway. Since it binds to and hinders Smo, thus, preventing the systemic activation of the forward signaling, it has been used in the clinical treatment of basal cell carcinoma (15). Cyclopamine, a plant steroidal alkaloid that inhibits Smo, is a therapeutic strategy for PCa $(16,17)$ and renal cell cancer (18). GANT61, a small molecule antagonist directly acting on downstream molecule Gli of the Hh signaling pathway, could interfere with cellular DNA binding of Glis (19). It has been reported that the Hh pathway is involved in PCa development, progression, treatment resistance $(20,21)$ and epithelial-mesenchymal transition (17). An increasing number of studies have reported that the Hh signaling pathway is associated with chemotherapeutic drug resistance in pancreatic cancer and other tumors (22-24). In addition, there is a crosstalk between the $\mathrm{Hh}$ and AR signaling pathways in PCa cells $(25,26)$. Since, however, the role of the Hh signaling pathway in CRPC cells is unclear, we hoped to determine whether it can regulate the drug sensitivity of CRPC cells to enzalutamide by interacting with the AR.

The aim of the present study was to assess whether PLCE and/or GANT61 can increase the sensitivity of CRPC cells to enzalutamide, and determine the interaction mechanism among PLC $\varepsilon$, Gli and AR, so as to provide a better strategy for the clinical treatment of CRPC. In the present study, the expression of PLCE and Gli-1/Gli-2 in benign prostatic hyperplasia (BPH), PCa and CRPC tissues and cells was investigated. The correlation between the PLC $\varepsilon$ and Gli-1/Gli-2 in CRPC tissues and cell lines was also explored. Furthermore, the effect of PLC $\varepsilon$ on cell proliferation and invasion was assessed in CRPC cell lines, and the sensitivity of EN-R and 22RV1 cells to enzalutamide following the downregulation of PLC $\varepsilon$ expression was determined using lentiviral-mediated shPLC $\varepsilon$ and/or treatment with specific Gli inhibitor GANT61. The results showed that the PLC $\varepsilon$ knockdown inhibits CRPC cell proliferation and invasion and sensitizes CRPC cells to enzalutamide by suppressing the AR expression and nuclear translocation. It was also shown that GANT61 combined with PLC $\varepsilon$ knockdown significantly sensitized CRPC cells to enzalutamide. These findings may provide a new therapeutic approach for CRPC.

\section{Materials and methods}

Patients and tissue samples. A total of $30 \mathrm{BPH}$ tissue samples, $64 \mathrm{PCa}$ tissue samples and 27 CRPC tissue samples were obtained from patients who underwent needle biopsy, transurethral resection of the prostate or radical prostatectomy at the Department of Urology of the First Affiliated Hospital of Chongqing Medical University, Chongqing, China between April 2010 and September 2015. Complete clinical data were available for all patients. All patients met the EAU guidelines for diagnostic criteria for BPH, PCa and CRPC. All tissue samples were reviewed by a pathologist for the confirmation of BPH or PCa. The study was approved by the Ethics Committee of Chongqing Medical University, Chongqing, China. Informed consent was obtained from the patients or their family members.

Immunohistochemistry assay. All formalin-fixed and paraffin-embedded tissue samples were cut into 5- $\mu \mathrm{m}$-thick sections. Immunohistochemical staining was performed using a standard immunoperoxidase staining procedure (anti-PLCE; dilution 1:50; Santa Cruz Biotechnology, Inc., Dallas, TX, USA; anti-Gli-1, dilution 1:200 and anti-Gli-2, dilution 1:150; both were from Abcam, Cambridge, UK). The expression status of immunostaining was reviewed and scored based on the proportion of positive cells and staining intensity by a pathologist. Staining intensity was scored as follows: 0 (no staining); 1 (light yellow); 2 (light brown); 3 (brown); and 4 (deep brown). Immunoreactivity ratio was scored as follows: 0 ( $0 \%$ immunoreactive cells), 1 ( $<5 \%$ immunoreactive cells), 2 (5-50\% immunoreactive cells), 3 ( $>50-75 \%$ immunoreactive cells) and 4 (>75\% immunoreactive cells). The final immunoreactivity score was defined as the sum of both parameters. Final scores of $\leq 1$ were regarded as negative expression, while scores of $\geq 2$ were regarded as positive.

Cell culture, treatment and transfection. Human PCa cell lines LNCaP and 22RV1 were obtained from the American Type Culture Collection (ATCC; Manassas, VA, USA), enzalutamide-resistant (EN-R) cells were generated as previously described (27). Briefly, the LNCaP cells, one of the androgen-dependent $\mathrm{PCa}$ cell strains, were treated with enzalutamide (10 $\mu \mathrm{M}$; Selleck Chemicals, Houston, TX, USA) for at least 6 months. 22RV1 and EN-R cells represent CRPC cells. All the cell lines were cultured in RPMI-1640 medium supplemented with $10 \%$ fetal bovine serum (FBS; both from Thermo Fisher Scientific, Inc., Waltham, MA, USA) and $1 \%$ penicillin/streptomycin (Beyotime Institute of Biotechnology, Haimen, China). Lentivirus-shRNA targeting human PLCE (LV-shPLCE, 5'-GGTTCTCTCCTAGAAGCA ACC-3') and the negative control (LV-shNC, 5'-TTCTCC GAACGTGTCACGT-3') were purchased from Shanghai GenePharma Co., Ltd. (Shanghai, China). A PLC $\varepsilon$ shRNA sequence was inserted into a pGLV3/H1/GFP-Puro lentivirus 
vector. Puromycin $(1 \mu \mathrm{g} / \mathrm{ml})$ was used to screen the stable cell lines. Fluorescence expression was observed under a fluorescence microscope (Olympus Corp., Tokyo, Japan) 3 days after lentiviral infection. The infected cells were cultured for one week for subsequent experiments. The PLC knockdown efficiency was assessed using RT-qPCR and western blot analysis. The human Gli-1 and Gli-2 expression plasmids ad-Gli1 and ad-Gli2 containing full-length of Gli-1, Gli-2 and control vectors Gli1-NC, Gli2-NC were purchased from Shanghai GenePharma Co., Ltd. Transient transfection was performed using Lipofectamine 2000 transfection reagent (Thermo Fisher Scientific, Inc.) according to the manufacturer's instructions. Other reagents used in the present study were as follows: Lipopolysaccharides (LPS; Merck KGaA, Darmstadt, Germany), GANT61 (MedChemExpress Co., Ltd., Shanghai, China).

Reverse transcription quantitative polymerase chain reaction $(R T-q P C R)$. RNA was isolated from cells using TRIzol (Takara Bio, Inc., Otsu, Japan) and reverse transcription was performed using the PrimeScript RT reagent kit, according to the manufacturer's instructions (Takara Bio, Inc.). RT-qPCR was performed on a CFX Connect qPCR system (Bio-Rad Laboratories, Inc., Hercules, CA, USA) with the SYBR Premix Ex Taq II kit (Takara Bio, Inc.). The primer sequences used were as follows: PLCE (sense), 5'-GCAACTACAACGCTG TCATGGAG-3' and PLC $\varepsilon$ (antisense), 5'-GCAACTACAACG CTGTCATGGAG-3'; Gli-1 (sense), 5'-ATCCTTACCTCC CAACCTCTGT-3' and Gli-1 (antisense), 5'-AACTTCTGG CTCTTCCTGTAGC-3'; Gli-2 (sense), 5'-CGGTGTAGGCAG AGCTGATG-3' and Gli-2 (antisense), 5'-CCACAAGGCAGA AACACCAA-3'; Smo (sense), 5'-CTCCTACTTCCACCTGCT CAC-3' and Smo (antisense), 5'-CAAAACAAATCCCACTCA CAGA-3'; $\beta$-actin (sense), 5'-TGACGTGGACATCCGCAA AG-3' and $\beta$-actin (antisense), 5'-CTGGAAGGTGGACAG CGAGG-3'. The RT-qPCR comprised an initial denaturation at $95^{\circ} \mathrm{C}$ for $15 \mathrm{sec}$, and then 45 cycles at $95^{\circ} \mathrm{C}$ for $5 \mathrm{sec}$ and $60^{\circ} \mathrm{C}$ for $30 \mathrm{sec}$. The mRNA expression levels were calculated using the comparative $2^{-\Delta \Delta \mathrm{Cq}}$ method (28), with $\beta$-actin as a calibrator. All gene expression experiments were repeated at least 3 times.

Cell Counting Kit-8 (CCK-8) assay. Cell proliferation was evaluated using the CCK- 8 assay. The cells were seeded in 96-well plates $\left(2,000\right.$ cells/well), and incubated at $37^{\circ} \mathrm{C}$ for $12 \mathrm{~h}$, and then cultured with the different treatment agents in each 5 replicate wells. CCK-8 reagent (10 $\mu \mathrm{l}$; Beijing Solarbio Science \& Technology Co., Ltd., Beijing, China) was added into each well and incubated at $37^{\circ} \mathrm{C}$ for $2 \mathrm{~h}$. Optical density was detected using a microplate reader at the absorbance of $450 \mathrm{~nm}$. Half maximal inhibitory concentration $\left(\mathrm{IC}_{50}\right)$ of enzalutamide in the cells was calculated by the CCK- 8 assay. The pretreated cells were seeded into 96 -well plates $(4,000$ cells/well $)$ and incubated at $37^{\circ} \mathrm{C}$ for $12 \mathrm{~h}$. Different concentrations $(0.2-640 \mu \mathrm{M})$ of enzalutamide were added to the cells in each 3 replicate wells for $24 \mathrm{~h}$, dimethyl sulfoxide (DMSO) (Merck KGaA) was used as the control. According to the research of Gonnissen et al (29), GANT61 inhibited the survival rate of 22RV1 cells in a dose-dependent manner (from 1 to $50 \mu \mathrm{M})$, but the survival rate was significantly inhibited at a concentration of $10 \mu \mathrm{M}$. Considering the cytotoxicity, the concentration of $10 \mu \mathrm{M}$ was chosen for the present study.

Transwell invasion assay. For the Transwell invasion assay, $1 \times 10^{4}$ cells were plated in serum-free medium in the upper chamber with a Matrigel-coated membrane, and the lower chamber was filled with medium supplemented with $10 \%$ FBS. Following $48 \mathrm{~h}$ of incubation, the cells at the lower chamber inserts were stained with $0.1 \%$ crystal violet and $4 \%$ formaldehyde (Beyotime Institute of Biotechnology) at room temperature for $15 \mathrm{~min}$. After removing the membrane, the number of cells was counted under a fluorescence microscope (Nikon, Tokyo, Japan).

Colony formation assay. The cells were plated in 6-well plates (400 cells/well), and the medium was refreshed every 3 days. Following culture for 14 days, the cells were fixed in $70 \%$ ethanol and then stained with $0.05 \%$ crystal violet solution for $20 \mathrm{~min}$. The number of colonies was counted under a light microscope.

Western blot assay. The total protein of cells was extracted using RIPA buffer supplemented with protease inhibitor PMSF and phosphatase inhibitors $\mathrm{NaF}$ and $\mathrm{Na}_{3} \mathrm{VO}_{4}$ (Roche Diagnostics, Basel, Switzerland). The protein concentration was determined using the BCA protein assay kit. The isolated proteins (50 $\mu \mathrm{g}$ per lane) were separated by sodium dodecyl sulfate-polyacrylamide gel (10 or $12 \%$ ) electrophoresis (SDS-PAGE) and transferred to polyvinylidene difluoride membranes (EMD Millipore, Billerica, MA, USA). The membranes was immersed in Tris-buffered saline (TBS) with Tween-20 blocking solution containing 5\% non-fat milk for $2 \mathrm{~h}$, and then incubated with the primary antibodies at $4^{\circ} \mathrm{C}$ overnight. The membranes were then incubated with a goat anti-rabbit IgG secondary antibody (dilution 1:2,000; cat. no. TA130015; OriGene Technologies, Inc., Rockville, MD, USA) or a goat anti-mouse IgG secondary antibody (dilution 1:2,000; cat. no. TA130001; OriGene Technologies, Inc.) for $1 \mathrm{~h}$ at $37^{\circ} \mathrm{C}$. The enhanced chemiluminescent (ECL) kit was purchased from Merck Millipore. The intensity level of each protein band was quantified using Image-Pro plus 6.0 (Media Cybernetics, Inc., Rockville, MD, USA). The following antibodies were used: PLCE (dilution 1:300; cat. no. sc28402; Santa Cruz Biotechnology, Inc.), STAT3 (dilution 1:1,000; cat. no. ab119352; Abcam), p-STAT3 (dilution 1:1,000; cat.no. ab32143; Abcam), Gli-1 (dilution 1:500; cat. no. ab49314; Abcam), Gli-2 (dilution 1:500; cat. no. ab26056; Abcam), Smo (dilution 1:500; cat. no. ab113438; Abcam) and AR (dilution 1:500; cat. no. sc7305; Santa Cruz Biotechnology, Inc.).

Immunofluorescence. EN-R cells $\left(1.0 \times 10^{5}\right.$ cells/well) were seeded on sterile glass coverslips and incubated for $48 \mathrm{~h}$, fixed in 4\% paraformaldehyde for $20 \mathrm{~min}$, and incubated with anti-AR primary antibody overnight at $4^{\circ} \mathrm{C}$. They were then cultured with a goat anti-rabbit secondary antibody (dilution 1:2,000; cat. no. TA130015; OriGene Technologies, Inc., Rockville, MD, USA) for $45 \mathrm{~min}$ in the dark at room temperature, and nuclei were stained with 4'6-diamidino-2-phenylindole (DAPI). Immunofluorescent images were acquired using a fluorescence microscope (Nikon, Tokyo, Japan) at a magnification of $\mathrm{x} 400$. 
A

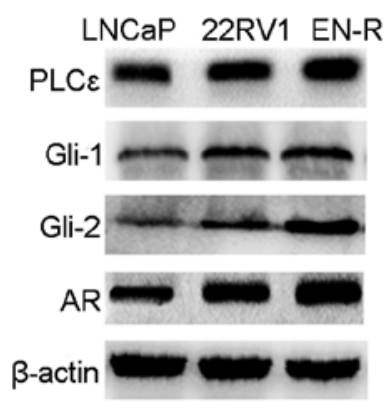

C

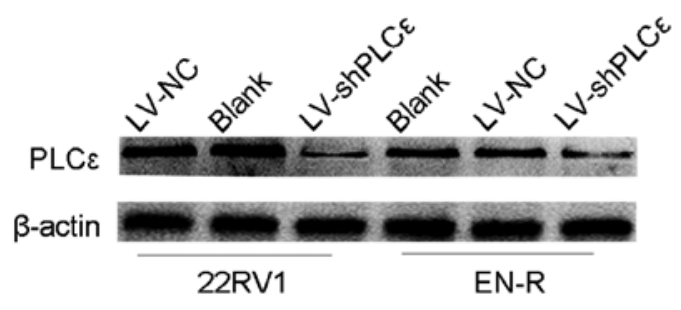

B

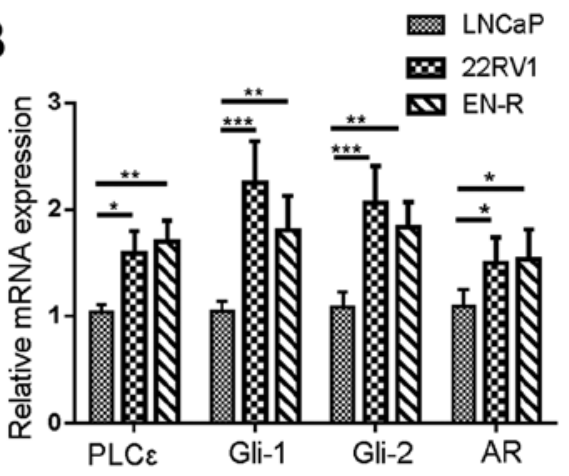

D

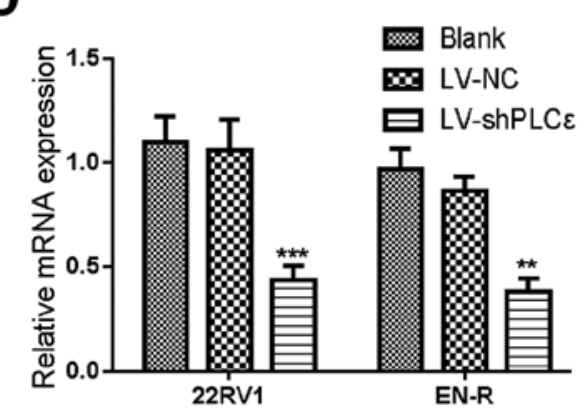

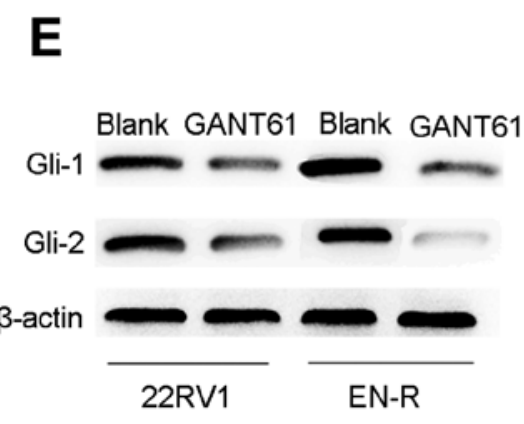

$\mathbf{F}$

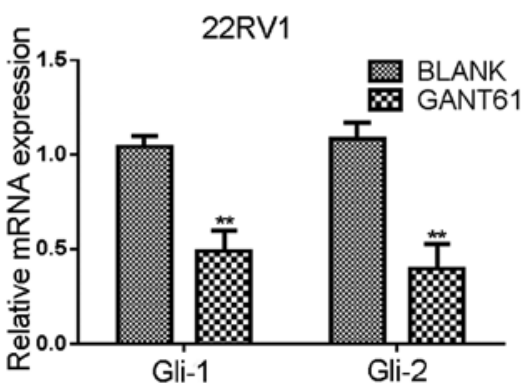

G

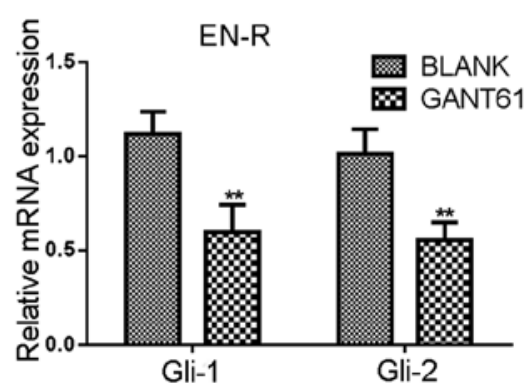

Figure 1. Lentivirus-shPLC $\varepsilon$ and GANT61 inhibit the protein and mRNA expression level of PLC $\varepsilon$ and Gli-1/Gli-2. (A) PLC $\varepsilon$ was highly expressed in the $\mathrm{PCa}(\mathrm{LNCaP})$ and CRPC (22RV1 and EN-R) cell lines. Gli-1/Gli-2 and AR expression levels were higher in CRPC (22RV1 and EN-R) cells compared to PCa (LNCaP) cells as shown by western blotting. (B) The mRNA expression levels of PLC $\varepsilon$, Gli-1/Gli-2 and AR in LNCap, 22RV1 and EN-R cells were detected by RT-qPCR ("P<0.05, ${ }^{* *} \mathrm{P}<0.01$ and $\left.{ }^{* * * *} \mathrm{P}<0.001\right)$. (C) PLC $\varepsilon$ knockdown was induced by transfecting lentivirus (LV)-shPLC $\varepsilon$ into CRPC cell line. Total cellular proteins were detected by western blotting. (D) Relative PLC $\varepsilon$ mRNA expression level was determined by RT-qPCR. $\beta$-actin was used as an internal control $\left({ }^{* * *} \mathrm{P}<0.01\right.$ and ${ }^{* * * *} \mathrm{P}<0.001$ compared with the blank control). (E-G) GANT61 inhibited the protein and mRNA expression level of Gli-1/Gli-2. $\beta$-actin was used as an internal control (** $\mathrm{P}<0.01$ compared with the blank control). PLC $\varepsilon$, phospholipase C $\varepsilon$; Gli, glioma-associated homolog; PCa, prostate cancer; CRPC, castration-resistant PCa; EN-R, enzalutamide-resistant cell line; AR, androgen receptor; RT-qPCR, reverse transcription quantitative polymerase chain reaction.

Animalxenograftmodel. All animal experiments were approved by the Ethics Committee of Chongqing Medical University (Chongqing, China). Twelve male castrated athymic nude mice aged 4 weeks (BALB/c; Beijing Huafukang Bioscience Co., Ltd., Beijing, China) weighing 18-20 g were raised in a cabinet with laminar air flow under pathogen-free conditions in a humidity- and temperature-controlled environment with a $12 \mathrm{~h} \mathrm{light/dark} \mathrm{schedule.} \mathrm{The} \mathrm{mice} \mathrm{had} \mathrm{ad} \mathrm{libitum} \mathrm{access}$ to food and water. Prior to the study initiation, the mice were allowed to acclimatize for 1 week. Then the mice were injected subcutaneously with $2 \times 10^{6} \mathrm{EN}-\mathrm{R}$ (Cont group) or LV-shPLCe EN-R (LV-shPLC $\varepsilon$ group) cells (suspended in $0.1 \mathrm{ml}$ Matrigel) into the right flank area. The animals were then divided into four groups: The Cont+PBS, the LV-shPLCE+PBS, the Cont+Enz and the LV-shPLCe+Enz (3 mice per group). A week later, the mice were treated with vehicle phosphate-buffered saline (PBS) or enzalumatide at $10 \mathrm{mg} / \mathrm{kg}$ by oral gavage (5 days on and 2 days off) up to 32 days treatment. The tumor growth was monitored every 5 days and the tumor volume was calculated using the following formula: Volume $\left(\mathrm{mm}^{3}\right)=1 / 2 \mathrm{x}$ length $\mathrm{x}$ width ${ }^{2}$. At the end of the experiment or when the tumor volume exceeded $1,000 \mathrm{~mm}^{3}$, the mice were euthanized with cervical dislocation and the tumors were collected and measured. The following animal humane endpoints were established: tumors exceeding $10 \%$ of the body weight of mice, tumors that became festered and infected, and mice that could not eat and drink water on their own. Mice were euthanized when these humane endpoints occurred. 
A

EN-R

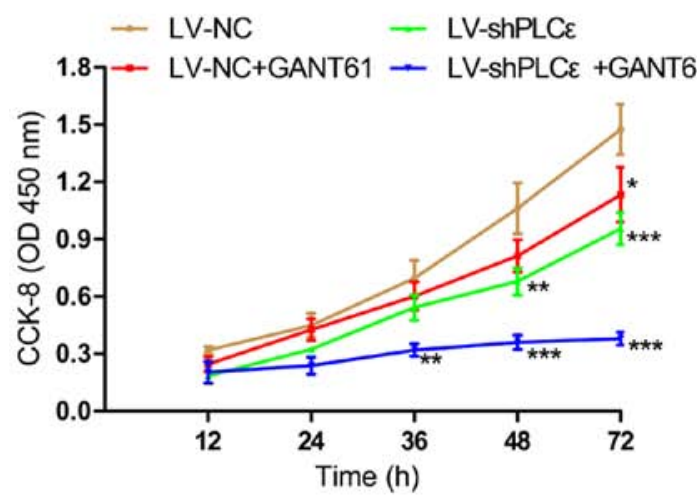

C 22RV1
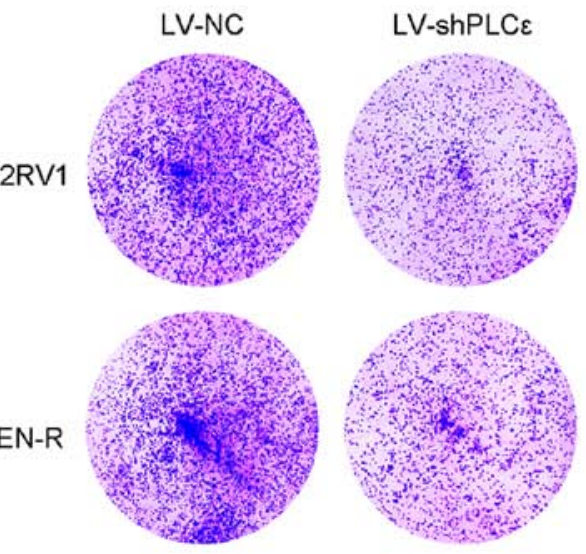

D
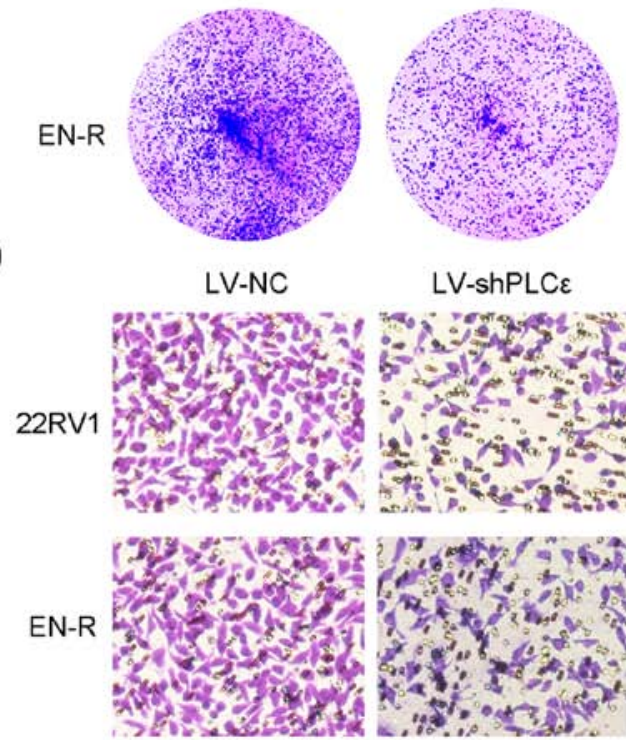

B
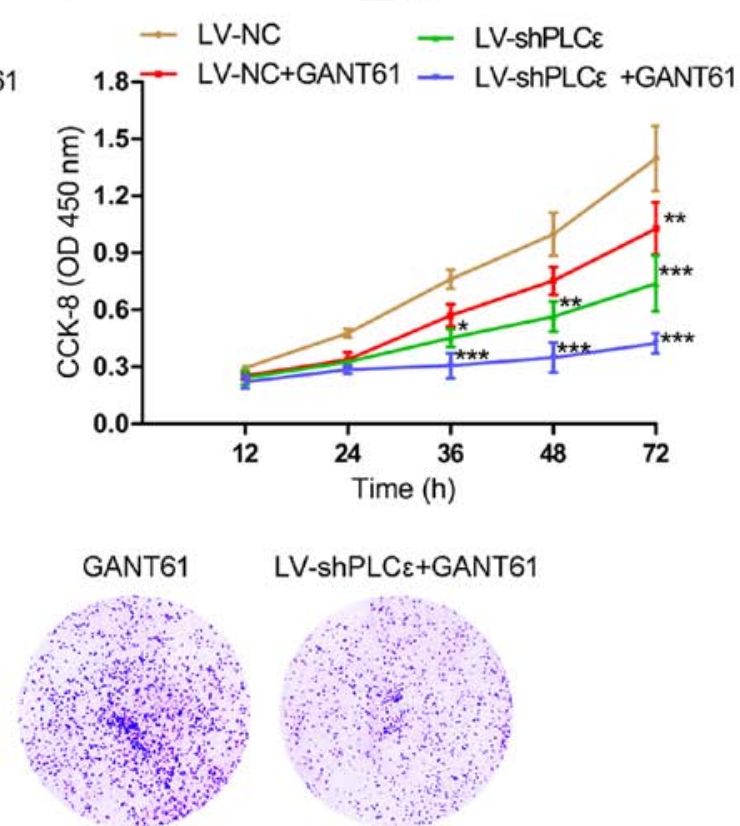

LV-shPLCE+GANT61
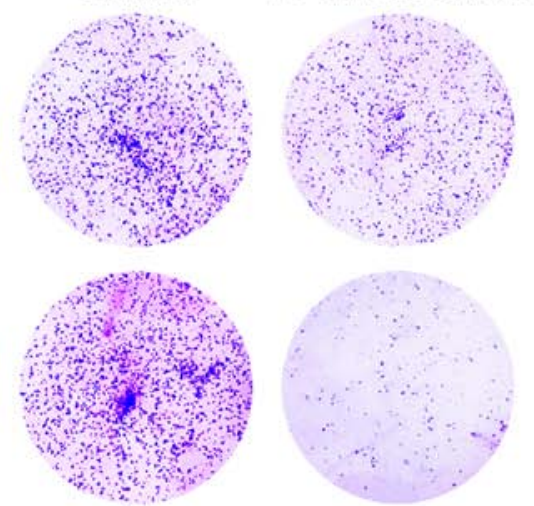

GANT61

LV-shPLC $\varepsilon+$ GANT61

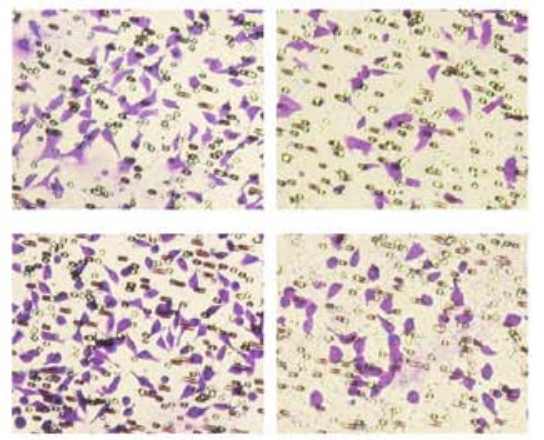

Figure 2. PLCe knockdown and Gli-1/Gli-2 inhibition suppress cell proliferation and invasion in CRPC cells. (A and B) The cell viability of EN-R and 22RV1 cells was assessed by CCK-8 assay following treatment with LV-shPLC $\varepsilon$ and/or GANT61 $10 \mu \mathrm{M}$ for $72 \mathrm{~h}\left({ }^{*} \mathrm{P}<0.05,{ }^{* * *} \mathrm{P}<0.01\right.$ and ${ }^{* * * *} \mathrm{P}<0.001$, compared to LV-NC at the same time-points). (C) Colony forming efficiency of 22RV1 and EN-R cells detected by colony forming assay following treatment with LV-shPLC $\varepsilon$ and/or GANT61 $10 \mu \mathrm{M}$. (D) The invasive ability of the 22RV1 and EN-R cells following treatment with LV-shPLC $\varepsilon$ and/or GANT61 $10 \mu \mathrm{M}$ for $72 \mathrm{~h}$ (magnification, $\mathrm{x} 400$ ) was evaluated by Transwell assay. PLC $\varepsilon$, phospholipase Cع; Gli, glioma-associated homolog; CRPC, castration-resistant prostate cancer; EN-R, enzalutamide-resistant cell line; CCK-8, Cell Counting Kit-8.

Statistical analysis. SPSS 20.0 (IBM Corp, Armonk, NY, USA) was used to process data. Data are presented as the mean \pm standard deviation (SD). Data from two groups were analyzed by unpaired t-test and $>2$ groups were analyzed by one-way and two-way ANOVA with post hoc contrasts by the Student-Newman-Keuls (SNK) method. For the data of characteristics of the patient groups, Mann-Whitney test for 2 independent variables was used; Chi-square test was used for trend for the number of rows or columns $>2$; McNemar's test was used to compare the differences between the matched categorical variables; Pearson's Chi-square test was used for 2 groups of independent variables. Progressive-free survival (PFS) and overall survival (OS) curves were estimated using the Kaplan-Meier method. Correlation curve analysis for PLC $\varepsilon$ protein vs. corresponding Gli1 and Gli2 protein in CRPC specimens was conducted using Pearson's linear correlation analysis. $\mathrm{P}<0.05$ was considered to indicate a statistically significant difference.

\section{Results}

Inhibition of PLCE and Gli-1/Gli-2 suppresses the proliferation and invasion of CRPC cells. Western blot analysis and RT-qPCR were performed to investigate the protein expression and mRNA levels of PLC $\varepsilon$ and Gli-1/Gli-2 in the LNCaP, 22RV1 and EN-R cells. As shown in Fig. 1A and B, PLC $\varepsilon$ was highly expressed in 
Table I. Demographic and clinical characteristics of the PCa patients.

\begin{tabular}{|c|c|c|c|c|}
\hline \multirow[b]{2}{*}{$\begin{array}{l}\text { Patient characteristics } \\
\text { Total number }\end{array}$} & \multirow[b]{2}{*}{$\begin{array}{c}\text { Overall } \\
\mathrm{n}=64\end{array}$} & \multicolumn{2}{|c|}{ PLC $\varepsilon$} & \multirow[b]{2}{*}{ P-value } \\
\hline & & $\begin{array}{c}\text { Negative } \\
15 / 64(23 \%)\end{array}$ & $\begin{array}{c}\text { Positive } \\
49 / 64(77 \%)\end{array}$ & \\
\hline Age, years & & & & 0.405 \\
\hline Median & 69 & 65 & 70 & \\
\hline Quartiles 25-75 & $59-74$ & $58-74$ & $60-75$ & \\
\hline PSA ng/ml & & & & 0.108 \\
\hline Median & 47.41 & 82.14 & 38.46 & \\
\hline Quartiles 25-75 & $23.70-89.89$ & $31.18-144.35$ & $21.44-86.39$ & \\
\hline Histological stage, n (\%) & & & & $0.028^{\mathrm{a}}$ \\
\hline Ta-T1 & $27(42 \%)$ & $10(67 \%)$ & $17(35 \%)$ & \\
\hline $\mathrm{T} 2-\mathrm{T} 4$ & $37(58 \%)$ & $5(33 \%)$ & $32(65 \%)$ & \\
\hline Gleason score, n (\%) & & & & 0.053 \\
\hline$<7$ & $21(33 \%)$ & $8(53 \%)$ & $13(27 \%)$ & \\
\hline$\geq 7$ & $43(67 \%)$ & $7(47 \%)$ & $36(73 \%)$ & \\
\hline Bone metastases, n (\%) & & & & 0.147 \\
\hline Yes & $25(39 \%)$ & $6(40 \%)$ & $19(39 \%)$ & \\
\hline No & $39(61 \%)$ & $9(60 \%)$ & $30(61 \%)$ & \\
\hline
\end{tabular}

${ }^{\text {aS }}$ tatistically significant. PCa, prostate cancer; PLC $\varepsilon$, phospholipase Ce; PSA, prostate-specific antigen.

the three cell lines. Gli-1/Gli-2 was highly expressed in 22RV1 and ENR cells, but slightly expressed in the LNCaP cells. The expression of AR was also found to be higher in the 22RV1 and EN-R cells, as compared with the LNCaP cells.

As previously described $(12,13)$, PLCe knockdown inhibits the proliferation and invasion of PCa cells, but whether it has the same inhibitory effect on CRPC cells remains unknown. GANT61, a specific Gli inhibitor, has been reported to suppress the growth of tumor cells by inhibiting the expression of Gli-1/Gli-2 $(29,30)$. To determine the effect of targeting PLC $\varepsilon$ and Gli-1/Gli-2 on the proliferative and invasive capacity of 22RV1 and EN-R cells, lentivirus-shPLCe (LV-shPLCe) was used to knock down PLCe (Fig. 1C and D). Meanwhile, GANT61 $(10 \mu \mathrm{M})$ was used to inhibit the expression of Gli-1/Gli-2 in 22RV1 and EN-R cells (Fig. 1E-G). CCK-8 and colony formation assays showed that PLCE knockdown and GANT61 treatment suppressed the proliferation of the 22RV1 and EN-R cells. The combination of PLCe knockdown and GANT61 enhanced the inhibitory effect (Fig. 2A-C). Accordingly, Transwell assay showed that PLCe knockdown and GANT61 treatment inhibited the invasion of the 22RV1 and EN-R cells. The combination of PLCE knockdown and GANT61 enhanced the inhibitory effect (Fig. 2D). These findings indicated that PLC $\varepsilon$ knockdown and Gli-1/Gli-2 inhibition suppressed cell proliferation and invasion in CRPC cells.

Inhibition of PLCE sensitizes CRPC cells to enzalutamide in vitro. It is well known that $\mathrm{AR}$ amplification is responsible for CRPC. As previously mentioned, the knockdown of PLCE inhibited the expression of AR in PCa cells. The inhibition of Gli has been shown to regulate the activity of AR, rather than its expression (25). However, whether PLCe knockdown or Gli inhibition regulates the sensitivity of CRPC cells to enzalutamide by interacting with the AR signaling pathway remains unclear. We therefore hypothesized that the knockdown of PLCE and inhibition of Gli-1/Gli-2 could sensitize CRPC cells to enzalutamide. To test this, the $\mathrm{IC}_{50}$ value of enzalutamide for the LNCaP, 22RV1and EN-R cells was determined by CCK- 8 assay, as $1.89 \pm 0.86,38.54 \pm 9.58$ and $84.17 \pm 18.94 \mu \mathrm{M}$, respectively (Fig. 3A). The $\mathrm{IC}_{50}$ value was detected again in 22RV1and EN-R cells following treatment with LV-shPLCe, GANT61 $10 \mu \mathrm{M}$ or combination treatment. The data showed that, although both LV-shPLC $\varepsilon$ and GANT61 reduced the $\mathrm{IC}_{50}$ value of enzalutamide to varying degrees, the combination treatment significantly decreased the $\mathrm{IC}_{50}$ value of 22RV1 and EN-R cells, as compared to either single treatment (Fig. 3B and C). These data indicated that PLCE knockdown and Gli-1/Gli-2 inhibition could sensitize CRPC cells to enzalutamide in vitro.

PLCE knockdown inhibits the expression of Gli-1/Gli-2 through the non-canonical Hh signaling pathway in CRPC cells. As described above, the increase in PLC $\varepsilon$ expression was positively correlated with an increase in Gli-1/Gli-2 expression in PCa and CRPC tissue samples. In addition, PLCe knockdown or inhibition of Gli-1/Gli-2 expression had a similar inhibitory effect on cell proliferation and invasion in the 22RV1 and EN-R cells. Both helped sensitize 22RV1 and EN-R cells to enzalutamide in vitro. We therefore, hypothesized that there is an interaction between PLCe and Gli-1/Gli-2. In order to determine that interaction, western blot analysis and RT-qPCR were performed. PLCE knockdown inhibited the mRNA and protein expression levels of Gli-1/Gli-2, while their inhibition did not affect the expression of PLC $\varepsilon$ in 22RV1 and EN-R cells, 

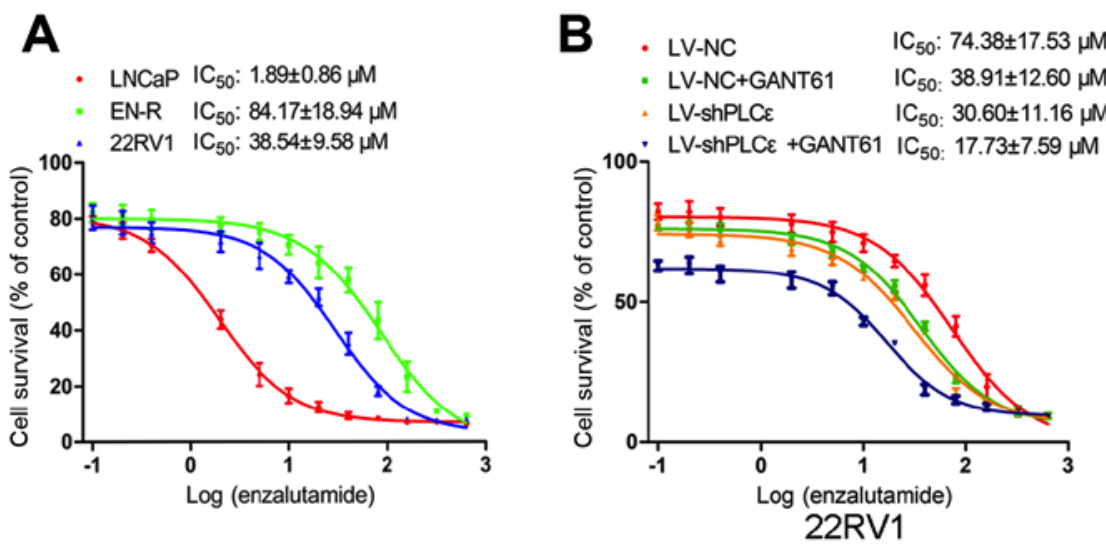

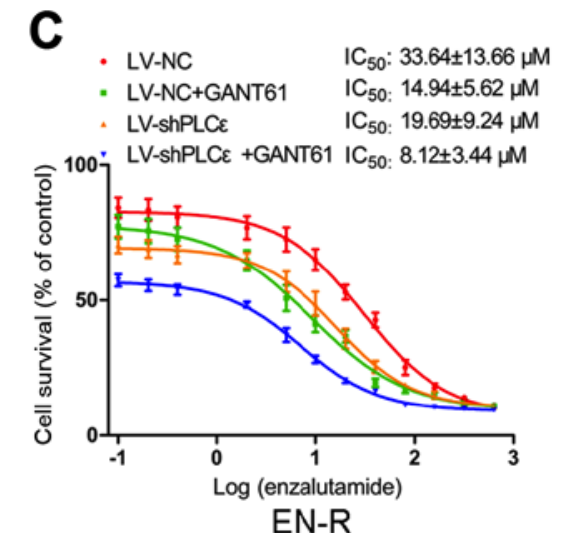

EN-R

D

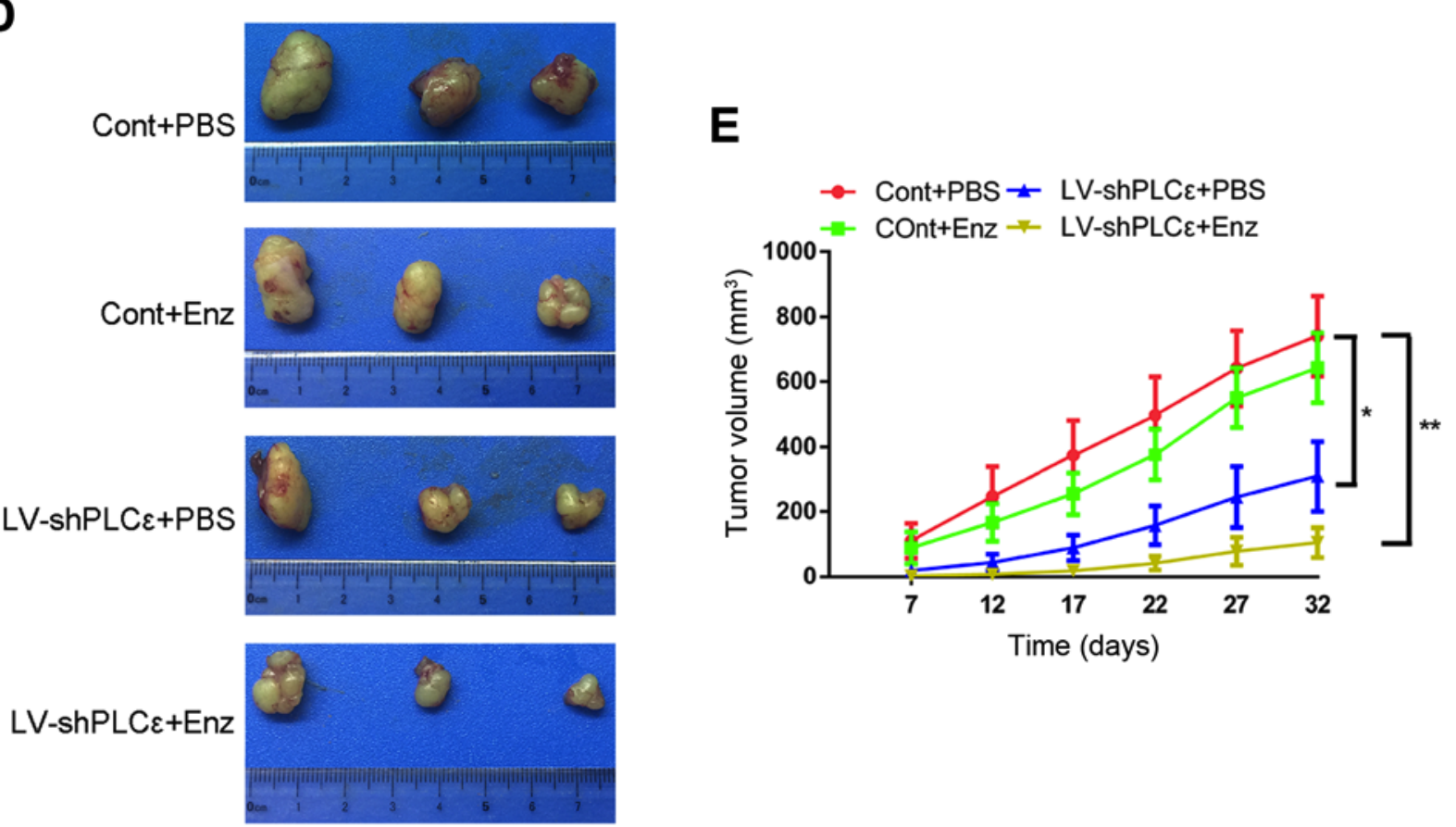

Figure 3. PLC $\varepsilon$ knockdown sensitizes CRPC cells to enzalutamide in vitro and in vivo. (A) LNCaP, 22RV1and EN-R cells were exposed to increasing concentrations of enzalutamide for $48 \mathrm{~h}$, and the $\mathrm{IC}_{50}$ was determined by CCK-8 assay. (B and C) 22RV1 and EN-R cells were exposed to increasing concentrations of enzalutamide for $48 \mathrm{~h}$, and the $\mathrm{IC}_{50}$ of 22RV1 and EN-R cells following treatment with LV-shPLC $\varepsilon$ and/or GANT61 $10 \mu \mathrm{M}$ was determined by CCK-8 assay. (D) Tumors sizes. (E) Dynamic growth of implanted tumors in mice $\left({ }^{*} \mathrm{P}<0.05 ;{ }^{* *} \mathrm{P}<0.01\right)$. PLC $\varepsilon$, phospholipase C $\varepsilon$; CRPC, castration-resistant prostate cancer; EN-R, enzalutamide-resistant cell line; $\mathrm{IC}_{50}$, half maximal inhibitory concentration; CCK-8, Cell Counting Kit-8; Enz, enzalutamide.

suggesting that PLC $\varepsilon$ is the upstream regulator of Gli-1/Gli-2 (Fig. 4). However, following PLCe knockdown, Smo (upstream regulatory gene of Gli in the classical Hh signaling pathway) showed no significant mRNA and protein expression change (Fig. 4). These data indicated that PLC $\varepsilon$ knockdown inhibited the expression of Gli-1/Gli-2 through the non-canonical $\mathrm{Hh}$ signaling pathway.

PLCE knockdown increases the sensitivity of CRPC cells to enzalutamide by suppressing $A R$ expression and nuclear translocation via different signaling pathways. To further investigate the mechanism by which PLCE increases the sensitivity of CRPC cells to enzalutamide, the effect of PLCe on AR expression and subcellular localization in EN-R cells was assessed using immunofluorescence and western blotting. It was found that PLCe knockdown inhibited AR translocation from the cytoplasm to the nucleus (Fig. 5A). Next, the overexpression of plasmid ad-Gliland ad-Gli2 was used to overexpress Gli-1 and Gli-2 in EN-R cells (Fig. 5B-D). Of note, it was found that the AR nuclear translocation was significantly increased in the LV-shPLCE+ad-Gli2 group compared to the LV-shPLCe+ad-Glil group (Fig. 5A). In addition, the cytoplasmic vs. nuclear distribution of AR in EN-R cells was examined using western blot analysis. The data showed that AR expression was decreased in the nucleus following PLC $\varepsilon$ knockdown, while the overexpression of Gli-2 reversed this effect (Fig. 5E), indicating that PLCe knockdown suppressed AR nuclear translocation via the Gli-2/AR signaling pathway.

The data also showed that the knockdown of PLCE inhibited the protein expression of AR but not its mRNA expression. However, the inhibition of the Gli-1/Gli-2 expression by GANT61 did not lead to any significant change in the AR mRNA and protein expression (Fig. 4). We also found that 
A

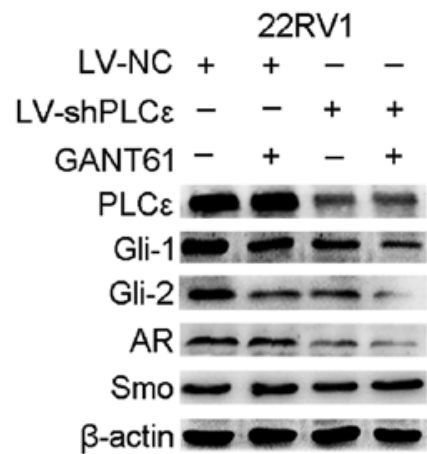

B

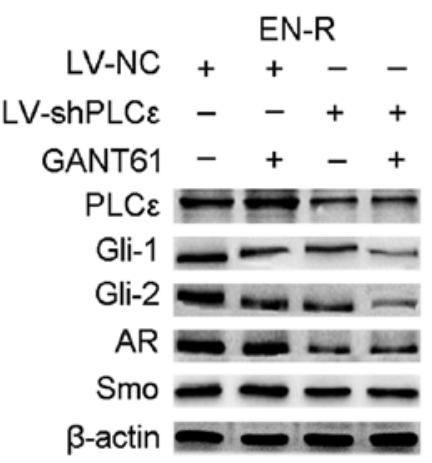

C

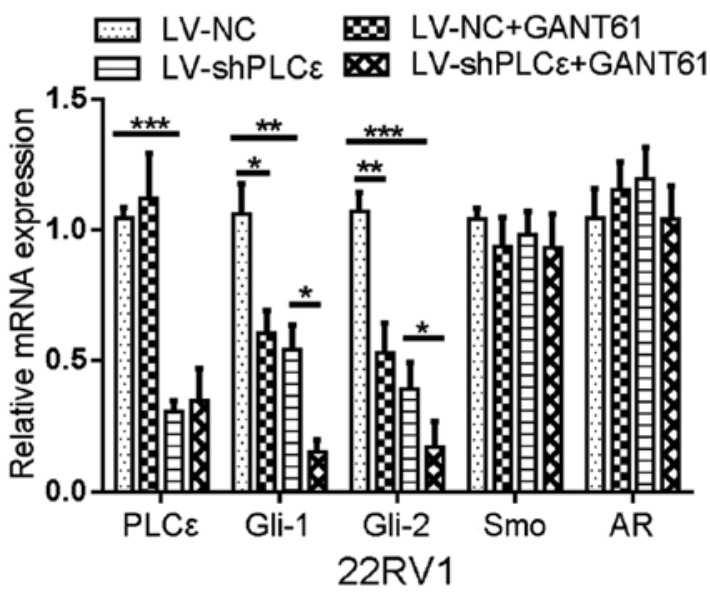

D

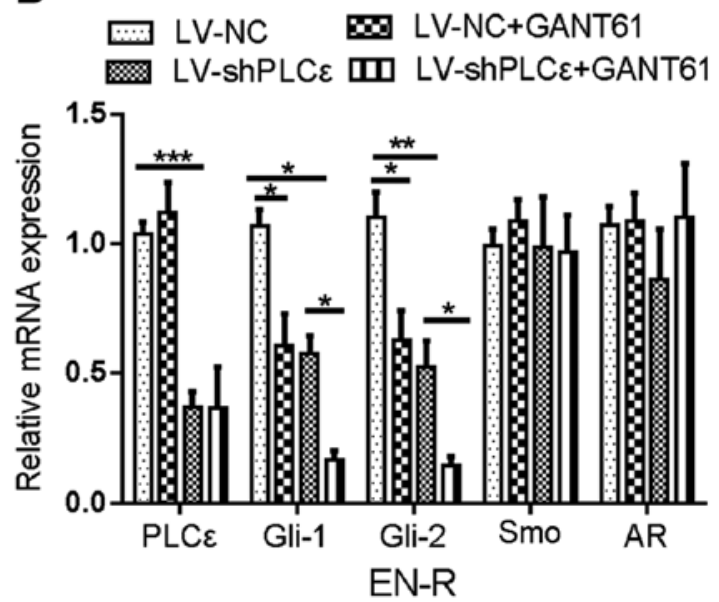

Figure 4. PLCe knockdown inhibits the expression of Gli-1/Gli-2. (A and B) The expression of PLCE, Gli-1, Gli-2, AR and Smo in 22RV1 and EN-R cells was examined by western blotting. The cells were treated with LV-shPLC $\varepsilon$ and/or GANT61 $10 \mu \mathrm{M}$ for $72 \mathrm{~h}$. $\beta$-actin served as a loading control. (C and D) The relative mRNA expression of PLC $\varepsilon$, Gli-1, Gli-2, AR and Smo in $22 \mathrm{RV} 1$ and EN-R cells was examined by $\mathrm{RT}-\mathrm{qPCR}\left({ }^{*} \mathrm{P}<0.05,{ }^{* *} \mathrm{P}<0.01\right.$ and $\left.{ }^{* * *} \mathrm{P}<0.001\right) . \mathrm{PLC} \varepsilon$, phospholipase C $\varepsilon$; Gli, glioma-associated homolog; AR, androgen receptor; Smo, smoothened; EN-R, enzalutamide-resistant cell line; RT-qPCR, reverse transcription quantitative polymerase chain reaction.

the protein expression of phosphorylated STAT3 (p-STAT3) was decreased following PLC $\varepsilon$ knockdown in EN-R cells, but there was no obvious change in the total STAT3 (t-STAT3) protein expression (Fig. 5I and J). We therefore hypothesized that PLCe affects the expression of AR through p-STAT3 signaling. To verify the role of the p-STAT3 signaling pathway and in the regulation of AR, LPS a p-STAT3 agonist, were used to activate p-STAT3. The data showed that the expression of p-STAT3 was activated by LPS, and that the activated p-STAT3 increased the expression of AR target gene PSA, rather than that of AR. PLCE knockdown inhibited the expression of p-STAT3 and PSA protein (Fig. 5F-H). These findings indicated that the knockdown of PLCE inhibited the PSA expression via the p-STAT3 signaling pathway.

PLCE inhibition sensitizes CRPC cells to enzalutamide in vivo. The role of LV-shPLC $\varepsilon$ in the sensitivity to enzalutamide in EN-R-derived tumors was also examined in vivo. Castrated nude mice were injected subcutaneously with $2 \times 10^{6} \mathrm{EN}-\mathrm{R}$ (Cont group) or LV-shPLCe EN-R cells (LV-shPLCe group) into the right flank area and then divided into four groups: Cont+PBS, LV-shPLC $\varepsilon+P B S$, Cont+Enz and LV-shPLC $\varepsilon+E n z$ ( $n=3$ per group). According to the research of Guerrero et al (31), 10 and $50 \mathrm{mg} / \mathrm{kg}$ of enzalutamide significantly inhibited the volume in a mouse LNCaP-AR xenograft model. Considering the toxicity of drugs, the dose of $10 \mathrm{mg} / \mathrm{kg}$ enzalutamide was chosen for animal experiments. The mice were treated with vehicle PBS or enzalutamide at $10 \mathrm{mg} / \mathrm{kg}$ by oral gavage (5 days on, 2 days off). The mice were then sacrificed, and tumors were collected and measured. No animal was sacrificed due to reaching humane endpoints. No mice were found to exhibit multiple tumors. The largest diameter of the tumors was $1.5 \mathrm{~cm}$. As shown in Fig. 3D and E, no significant difference was identified in the tumor volume between the Cont+PBS and the Cont+Enz groups. The tumor volume in the LV-shPLC $\varepsilon+\mathrm{PBS}$ group was smaller than that of the Cont+PBS and Cont+Enz groups. In addition, the LV-shPLCE+Enz group exhibited the smallest tumor volume of the four groups. These results suggested that PLC $\varepsilon$ knockdown inhibited the tumor growth of the EN-R cell xenografts and contributed to the sensitization of CRPC cells to enzalutamide in vivo.

Increased PLCE expression contributes to unfavorable disease phenotype and poor outcome of patients with PCa. A total of $30 \mathrm{BPH}$ samples, $64 \mathrm{PCa}$ and $27 \mathrm{CRPC}$ samples were collected (Table I). The expression of PLC $\varepsilon$ was detected in the BPH, PCa and CRPC tissues by immunohistochemistry. A high expression of PLC $\varepsilon$ was identified in most PCa (49/64) 
A

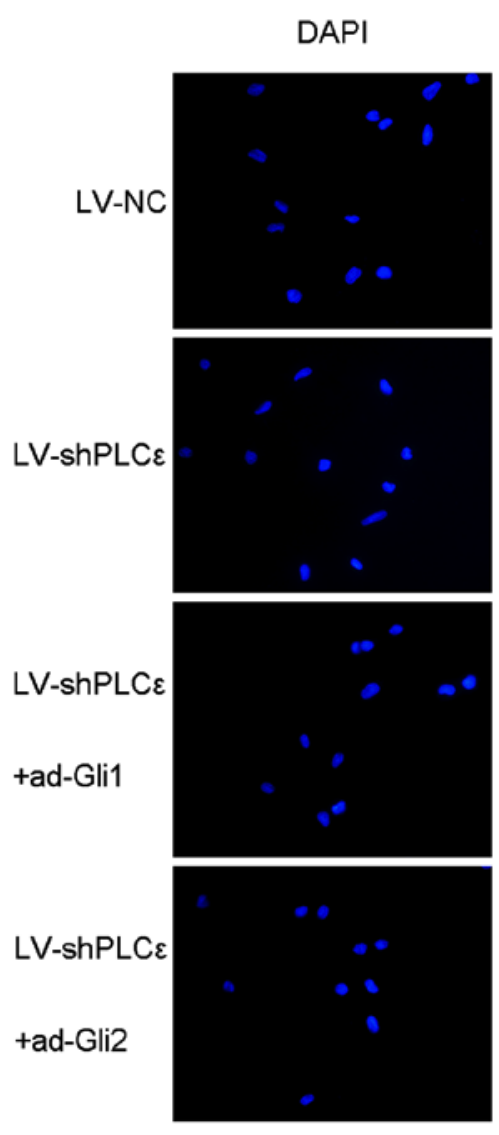

E
AR
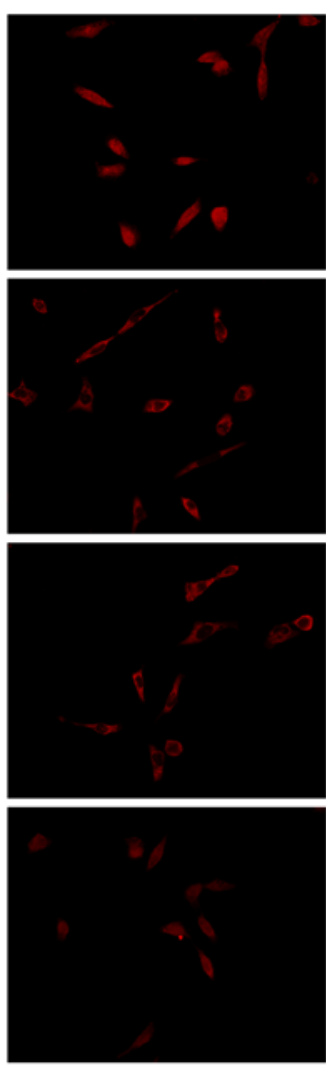

$\mathbf{F}$
B

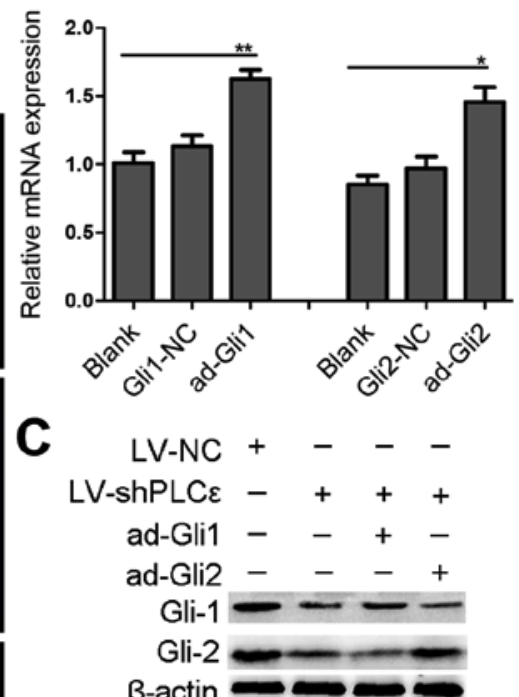

D

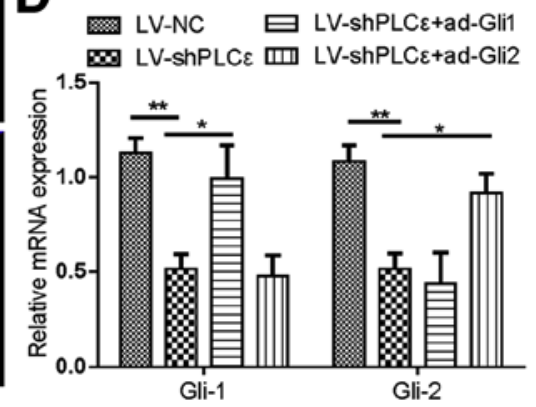

G

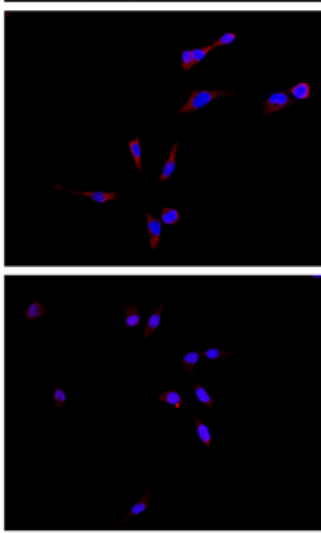

$\beta$-actin

EN-R

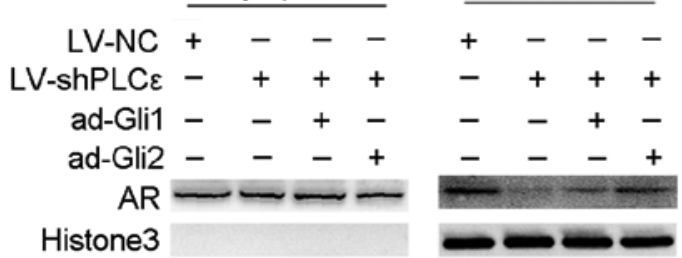

Histone3

$\beta$-actin

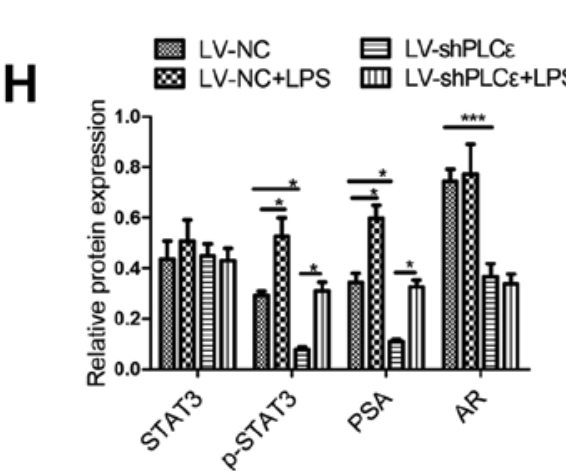

EN-R LV-NC ++LV-shPLC $\varepsilon-\ldots++$ LPS - + - +

STAT3 $-\cdots$ p-STAT3 $=$

PSA $=-\cdots$ AR

$\beta$-actin

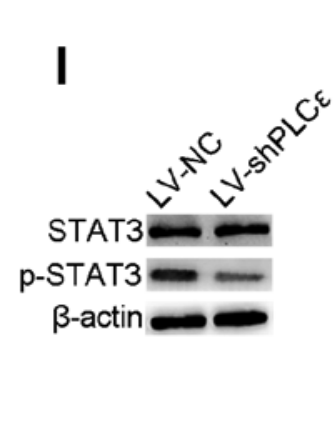

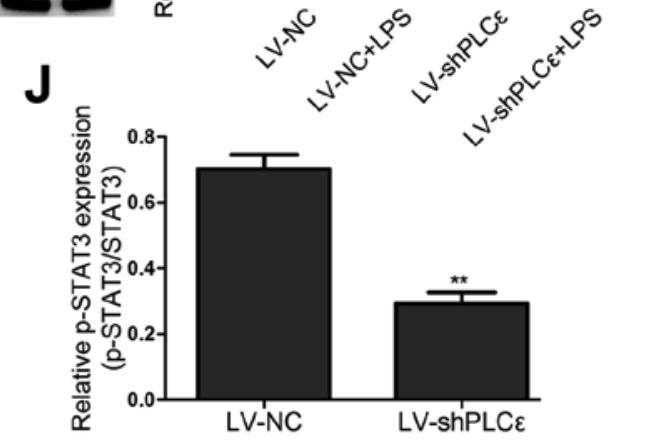

Figure 5. PLC $\varepsilon$ knockdown suppresses AR expression and nuclear translocation via different signaling pathways. (A) Immunofluorescence demonstrated AR intracellular distribution at $48 \mathrm{~h}$ following infection with LV-shPLC $\varepsilon$ and ad-Gli1/ad-Gli2 in EN-R cells. Magnification, x400. PLC $\varepsilon$ knockdown inhibited AR nuclear translocation in EN-R cells. However, the overexpression of Gli-2 reversed the inhibitory effect produced by PLCE. (B) The relative mRNA expression level of Gli-1 and Gli-2 following treatment with an overexpression plasmid of ad-Gli1, ad-Gli2 was examined by RT-qPCR and $\beta$-actin served as loading control (NC stands for empty vector plasmid group $\left({ }^{*} \mathrm{P}<0.05,{ }^{* *} \mathrm{P}<0.01\right)$. (C) Protein expression level of Gli-1 and Gli-2 following treatment with the overexpression plasmid of ad-Gli1, ad-Gli2 and PLC $\varepsilon$ knockdown. (D) The mRNA expression level of Gli-1 and Gli-2 following treatment with overexpression plasmid of ad-Gli1, ad-Gli2 and PLC $\varepsilon$ knockdown $\left({ }^{*} \mathrm{P}<0.05,{ }^{* *} \mathrm{P}<0.01\right)$. (E) Western blotting showed that PLC $\varepsilon$ knockdown significantly decreased the AR expression in the nucleus. However, the expression of AR in the nucleus increased following Gli-2 overexpression. (F-H) Western blotting indicated that PLC $\varepsilon$ knockdown inhibited the PSA expression via the p-STAT3 signaling pathway (The results are represented as the mean $\pm \mathrm{SD} ;{ }^{*} \mathrm{P}<0.05,{ }^{* *} \mathrm{P}<0.01$ and ${ }^{* * *} \mathrm{P}<0.001$ ). (I and J) Western blotting showed that the downregulation of PLC $\varepsilon$ decreased the p-STAT3 protein expression in EN-R cells (The results are represented as the mean $\left.\pm \mathrm{SD} ;{ }^{* *} \mathrm{P}<0.01\right)$. PLC $\varepsilon$, phospholipase $\mathrm{C} \varepsilon ; \mathrm{AR}$, androgen receptor; Gli, glioma-associated homolog; EN-R, enzalutamide-resistant cell line. 
Table II. Demographic and clinical characteristics of the CRPC patients.

\begin{tabular}{|c|c|c|c|c|}
\hline \multirow[b]{2}{*}{$\begin{array}{l}\text { Characteristics } \\
\text { Total number }\end{array}$} & \multirow[b]{2}{*}{$\begin{array}{c}\text { Overall } \\
\mathrm{n}=27\end{array}$} & \multicolumn{2}{|c|}{ PLC $\varepsilon$} & \multirow[b]{2}{*}{ P-value } \\
\hline & & $\begin{array}{l}\text { Negative } \\
6 / 27(22 \%)\end{array}$ & $\begin{array}{c}\text { Positive } \\
21 / 27(78 \%)\end{array}$ & \\
\hline Age, years & & & & 0.884 \\
\hline Median & 71 & 73 & 70 & \\
\hline Quartiles 25-75 & $65-77$ & $65-78$ & $66-79$ & \\
\hline PSA ng/ml & & & & 0.726 \\
\hline Median & 32.23 & 28.26 & 32.24 & \\
\hline Quartiles 25-75 & $16.76-56.18$ & $16.13-58.32$ & $24.90-58.12$ & \\
\hline Bone metastases, $\mathrm{n}(\%)$ & & & & $0.030^{\mathrm{a}}$ \\
\hline Yes & $15(56 \%)$ & $1(17 \%)$ & $14(67 \%)$ & \\
\hline No & $12(44 \%)$ & $5(83 \%)$ & $7(33 \%)$ & \\
\hline
\end{tabular}

${ }^{\text {aS }}$ tatistically significant. CRPC, castration-resistant prostate cancer; PLC $\varepsilon$, phospholipase C ; PSA, prostate-specific antigen.

and CRPC (21/27) tissue samples. By contrast, none of the BPH tissues stained positive for PLCE (Fig. 6A). Noticeably, the expression of PLCE in the CRPC tissues was significantly higher than that in the PCa tissues ( $\mathrm{P}=0.0447$; Fig. 6B). It was also observed that the expression of Gli-1 and Gli-2 in the tumor (PCa and CRPC) tissues was significantly higher than that in the benign (BPH) tissues (Fig. 6A, C and D). Interestingly, the expression of Gli-1, but not Gli-2, in the CRPC tissues was significantly upregulated, as compared to that in the $\mathrm{PCa}$ tissues ( $\mathrm{P}=0.152$; Fig. 6C). In addition, Pearson's linear correlation results showed that $\mathrm{PLC} \varepsilon$ expression was positively correlated with Gli-1 $(\mathrm{r}=0.581, \mathrm{P}=0.01$; Fig. $6 \mathrm{E})$ and Gli-2 expression ( $\mathrm{r}=0.409, \mathrm{P}=0.034$; Fig. $6 \mathrm{~F})$.

To investigate the effects of PLCE on the disease phenotype and patient clinical outcome in PCa and CRPC, the association between various clinical parameters and the PLCE expression in PCa and CRPC tissues was analyzed. On the one hand, it was found that the PLCE expression was positively correlated with the tumor histological stage of the PCa patients $(\mathrm{P}=0.028$; Table $\mathrm{I})$ and bone metastasis of the CRPC patients $(\mathrm{P}=0.030$; Table II). On the other hand, Kaplan-Meier survival analysis results showed that the median progression-free survival (PFS) was 24 months (95\% CI, 17-30 months) in the PLCE-positive CRPC patients, while the median PFS was 28 months (95\% CI, 21-35 months) in the PLC $\varepsilon$-negative patients; PLCe positivity in the CRPC tissues was associated with a shorter PFS in the CRPC patients $(\mathrm{P}=0.025$; Fig. 7A). Similarly, the overall survival (OS) of PCa patients with a negative PLCe expression was significantly longer than that of $\mathrm{PCa}$ patients with a positive $\mathrm{PLC} \varepsilon$ expression $(\mathrm{P}=0.027$; Fig. 7B). These findings revealed that high PLC $\varepsilon$ expression contributes to unfavorable disease phenotype and poor outcomes in patients with $\mathrm{PCa}$.

\section{Discussion}

As a member of the PLC family, PLCe does not only have typical catalytic domains $\mathrm{XY}$ and $\mathrm{C} 2$, but also a carboxyl-terminated Ras domain RA and amino acid guanylate exchange factor domain CDC25 $(32,33)$. These special domains can activate multiple signaling pathways and promote the development of malignant tumors. Current experimental and clinical data suggest that PLC $\varepsilon$ may play a pivotal role in the regulation of the development and progression of different types of cancer, such as skin cancer (10), lung cancer (34), gastric cancer and esophageal squamous cell carcinoma $(35,36)$. We previously investigated the expression level of PLCE in bladder cancer and renal cell carcinoma using immunohistochemistry. It was found to be significantly higher than that in normal tissue, suggesting that PLC $\varepsilon$ is closely associated with the occurrence and development of renal cell carcinoma and bladder cancer $(37,38)$. Recently, our research $(12,13)$ has shown that the high expression of PLCE is associated with cell proliferation and invasion in PCa. In the present study, it was found that the expression of PLCE was significantly increased in PCa and CRPC, as compared to BPH tissues, and that this high expression was linked to poor prognosis in patients with PCa. PLCe knockdown inhibited the proliferation and invasion of CRPC cells. These results revealed that PLCE is involved in the progression of CRPC and further demonstrated that PLC $\varepsilon$ is an oncogene, which is consistent with previous literature reports.

The activity of $\mathrm{Hh} / \mathrm{Gli}$ signaling has been shown to be elevated in PCa (20), and is more intensive in those of metastatic PCa than in specimens of localized-PCa (21). Consistent with these reports, it was found in the present study that $\mathrm{Hh} / \mathrm{Gli}$ signaling was markedly increased in CRPC, as compared to PCa tissues, suggesting that $\mathrm{Hh} / \mathrm{Gli}$ signaling plays an important role in the emergence and development of CRPC. In addition, it was found that the increase of PLCE was positively correlated with the increase in Gli-1/Gli-2 expression, and that PLC $\varepsilon$ knockdown and/or inhibition of Gli-1/Gli-2 using GANT61 inhibited the proliferation and invasion of CRPC cells. PLCE knockdown also interacted with the Hh/Gli signaling pathway by decreasing the mRNA and protein expression of the Hh target genes Gli-1 and Gli-2. However, Smo, the upstream regulatory gene of Gli did not decrease, suggesting that PLCE could be involved in the 
A
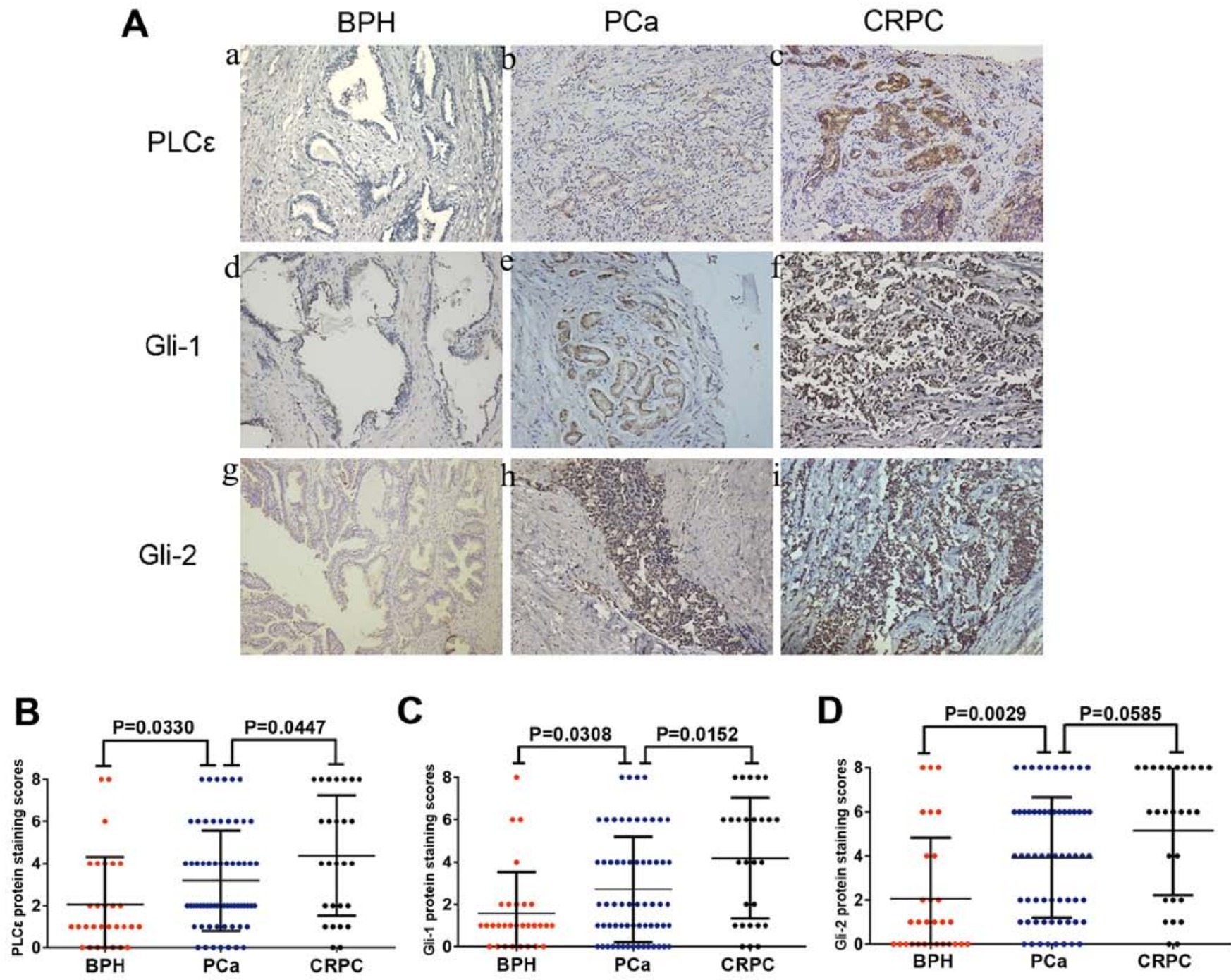

$\mathrm{E}$

\section{$\mathbf{F}$}
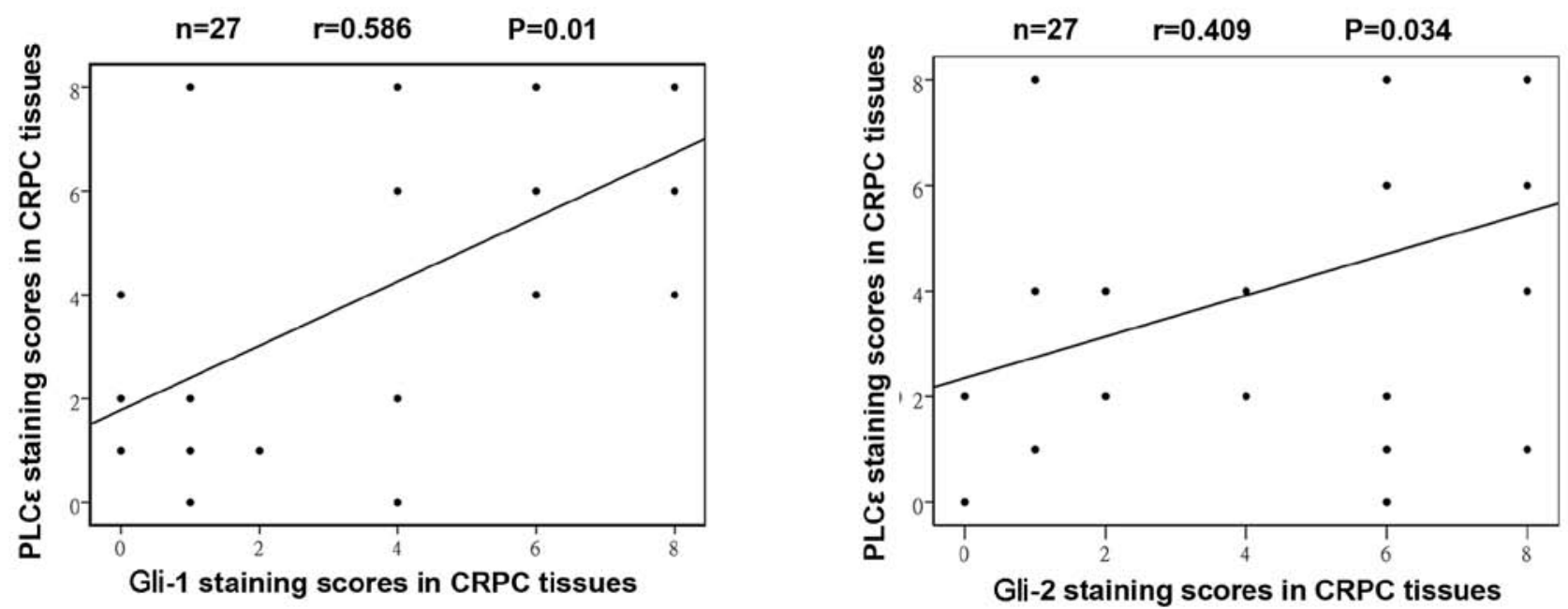

Figure 6. Increased PLC $\varepsilon$ expression in PCa and CRPC tissues is associated with Gli-1/Gli-2 expression. (A) Immunohistochemical staining in prostate tissues . Magnification, x200. (a, d and g) BPH tissues. (b, e and h) PCa tissues. (c, f and i) CRPC tissues. (B-D) Average staining scores for PLC , Gli-1 and Gli-2 in $\mathrm{BPH}, \mathrm{PCa}$ and CRPC tissues. (E and F) Correlation curve analysis for PLC $\varepsilon$ vs. Gli-1/Gli-2 staining scores in CRPC tissues. P $<0.05$ was considered statistically significant. PLC $\varepsilon$, phospholipase $\mathrm{C} \varepsilon ; \mathrm{BPH}$, benign prostatic hyperplasia; $\mathrm{PCa}$, prostate cancer; CRPC, castration-resistant PCa; Gli, glioma-associated homolog.

progression of CRPC cells through the non-canonical Hh/Gli signaling pathway.
Androgen-deprivation therapy (ADT) remains the main treatment strategy for PCa patients (39). However, the transition 
A

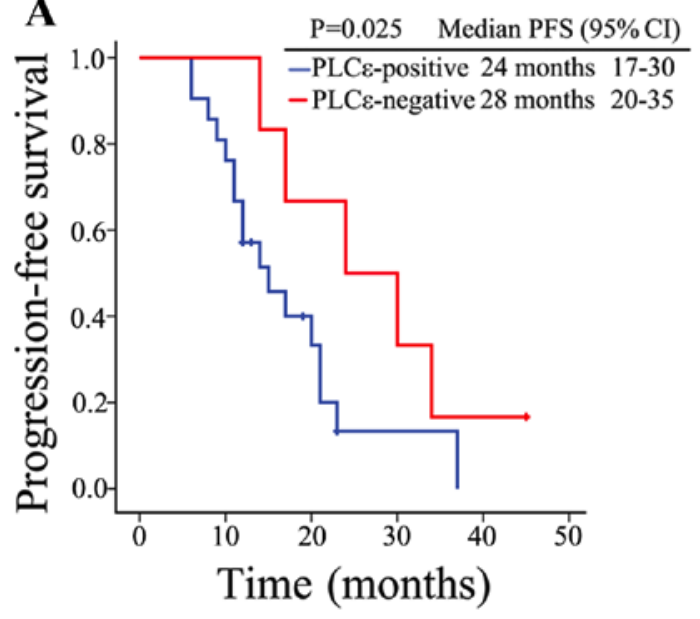

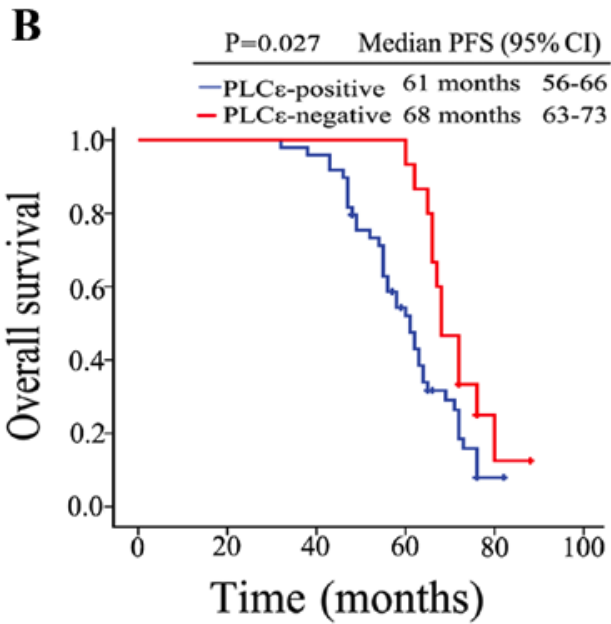

Figure 7. Increased PLC $\varepsilon$ expression in PCa and CRPC tissues is linked to poor prognosis. (A) Kaplan-Meier survival analysis of the PFS of 27 patients with CRPC (21 PLCe-positive, 6 PLCe-negative patients). (B) Overall survival cumulative Kaplan-Meier analysis for PCa patients (49 PLCe-positive and 15 PLC $\varepsilon$-negative patients). $\mathrm{P}<0.05$ was considered statistically significant. PLC $\varepsilon$, phospholipase C $\varepsilon$; PCa, prostate cancer; CRPC, castration-resistant PCa; PFS, progression-free survival; OS, overall survival; CI, confidence interval.

from hormone-sensitive PCa to CRPC is inevitable during treatment. AR amplification is a major mechanism of resistance to ADT (40). Enzalutamide is one of the first-line drugs for the treatment of CRPC; it has not only been shown to potently inhibit the binding of androgens to AR, but also the nuclear translocation and subsequent binding of the AR-ligand complex to DNA, thereby inhibiting the transcription of AR target genes (41). However, enzalutamide resistance can occur within a few months. In the present study, it was found that PLC $\varepsilon$ knockdown increased the sensitivity of CRPC cells to enzalutamide, which might be achieved by PLCe knockdown suppressing AR nuclear translocation via the Gli-2/AR signaling pathway, or PLCE knockdown inhibiting the expression of the AR target gene PSA via the p-STAT3 signaling pathway. Although PLCe knockdown decreased the protein expression of AR, we failed to determine the exact mechanism in this study.

GANT61, a specific Gli-1/Gli-2 inhibitor, has been reported to significantly decrease cell survival of PC3 and 22Rv1 cells (29). As a small molecule that blocks the transcription of essential Hh proteins, GANT61 has a broad spectrum of potential mechanisms (either through the specific inhibition of Hh signaling or not) by which it can elicit anticancer effects, as it targets many of the 'classical hallmarks of cancer' (42). In present study, GANT61 was shown to not only suppress proliferation and invasion in CRPC cells, but also sensitize CRPC cells to enzalutamide, suggesting that GANT61 may be a novel adjuvant drug for use in the treatment of CRPC. However, the potential mechanism of sensitization is unclear. Although it was demonstrated herein that downregulation of Gli-2, rather than Gli-1, inhibited AR translocation, that inhibition did not affect AR expression, which was consistent with a previous study on androgen-independent PCa cells (25). It was therefore deduced that GANT61 restored the sensitivity of CRPC cells to enzalutamide not only via the AR pathway, but also other non-AR pathways, such as cell autophagy. Autophagy is an important mechanism of resistance to enzalutamide in CRPC; GANT61 induces autophagy in cancer cells, and the enhancement of autophagy increases the sensitivity of enzalutamide in
CRPC $(43,44)$. Taken together, the signal transduction relationship among PLCE, Gli and AR was that: GANT61 inhibited AR nuclear translocation by inhibiting Gli2, GANT61 also increased the drug sensitivity of enzalutamide through other non-AR signaling pathways. PLCE inhibited the activity of $\mathrm{AR}$ axis in three ways. On the one hand, PLCE inhibited AR nuclear translocation by inhibiting the non-classical Hh/Gli-2 signaling pathway. On the other hand, PLCE inhibited the expression of AR target gene PSA by inhibiting the expression of p-STAT3. In addition PLCE inhibited the expression of AR protein, but the mechanism has not been clarified. Certain issues were encountered in this study, including the failure to define the mechanism through which PLCE affects AR protein expression and GANT61 affects drug sensitivity to enzalutamide in CRPC through non-AR pathways. Further research is required to confirm these. In immunohistochemical experiments, the expression status of immunostaining was reviewed and scored based on the proportion of positive cells and staining intensity by pathologist, and the staining intensity was defined as follows: 0 (no staining), 1 (light yellow), 2 (light brown), 3 (brown) and 4 (deep brown) and the immunoreactivity ratio was 0 ( $0 \%$ immunoreactive cells), $1(<5 \%$ immunoreactive cells), 2 (5-50\% immunoreactive cells), 3 (>50-75\% immunoreactive cells) and 4 (>75\% immunoreactive cells). The final immunoreactivity score was defined as the sum of both parameters. However, the lack of positive control is still a limitation of this study.

In combination, the present results showed that PLCE expression and $\mathrm{Hh} / \mathrm{Gli}$ signaling were excessively activated in the majority of CRPC tissues. PLCE positivity was linked to poor prognosis in patients with PCa. The knockdown of PLC $\varepsilon$ significantly suppressed CRPC cell proliferation and invasion by reducing Gli-1/Gli-2 expression. More importantly, PLCe knockdown increased the sensitivity of CRPC cells to enzalutamide by suppressing AR nuclear translocation via the Gli-2/AR signaling pathway and inhibiting PSA expression via the p-STAT3 signaling pathway. In addition, the combination of PLCE knockdown and GANT61 significantly 
sensitized CRPC cells to enzalutamide. Targeting PLC $\varepsilon$ may therefore serve as a potential treatment strategy for CRPC, and GANT61 may prove to be a promising agent for use in CRPC treatment.

\section{Acknowledgements}

The authors would like to thank Dr Dingyun Liu, Department of Pathology, Fuling Center Hospital of Chongqing City, Chongqing, China, for providing technical assistance with the immunohistochemistry assays.

\section{Funding}

The present study was supported by a grant from the Natural Science Foundation of China (no. 81802543).

\section{Availability of data and materials}

All data generated or analyzed during this study are included in this published article.

\section{Authors' contributions}

WS, XW and CL designed the experiments. WS, LL, ZD and MY collected the specimens and analyzed the clinical data. WS, LL, MY, YG, HC and ZQ conducted the experiments and collected the data. WS and LL co-wrote the manuscript. CL and XW provided technical support of this research project and supervised the progress of the experiments. ZD, ZQ and MY analyzed the statistical data. WS, LL and ZD assembled and designed the figures. All authors read and approved the final manuscript and agree to be accountable for all aspects of the research in ensuring that the accuracy or integrity of any part of the work are appropriately investigated and resolved.

\section{Ethics approval and consent to participate}

This study was approved by the Ethics Committee of Chongqing Medical University (Chongqing, China). Informed consent was obtained from the patients or their family members. All animal experiments were approved as well by the Ethics Committee of Chongqing Medical University.

\section{Patient consent for publication}

Not applicable.

\section{Competing interests}

The authors declare that they have no competing interests.

\section{References}

1. Siegel R, Ma J, Zou Z and Jemal A: Cancer statistics, 2014. CA Cancer J Clin 64: 9-29, 2014.

2. Du LB, Li HZ, Wang XH, Zhu C, Liu QM, Li QL, Li XQ, Shen YZ, Zhang XP, Ying JW, et al: Analysis of cancer incidence in Zhejiang cancer registry in China during 2000 to 2009. Asian Pac J Cancer Prev 15: 5839-5843, 2014

3. Qu M, Ren SC and Sun YH: Current early diagnostic biomarkers of prostate cancer. Asian J Androl 16: 549-554, 2014.
4. Liu C, Armstrong C, Zhu Y, Lou W and Gao AC: Niclosamide enhances abiraterone treatment via inhibition of androgen receptor variants in castration resistant prostate cancer. Oncotarget 7: 32210-32220, 2016.

5. Scher HI, Fizazi K, Saad F, Taplin ME, Sternberg CN, Miller K, de Wit R, Mulders P, Chi KN, Shore ND, et al: Increased survival with enzalutamide in prostate cancer after chemotherapy. $\mathrm{N}$ Engl J Med 367: 1187-1197, 2012.

6. Tombal B, Borre M, Rathenborg P, Werbrouck P, Van Poppel H, Heidenreich A, Iversen P, Braeckman J, Heracek J, Baskin-Bey E, et al: Long-term efficacy and safety of enzalutamide monotherapy in hormone-naïve prostate cancer: 1- and 2-year open-label follow-up results. Eur Urol 68: 787-794, 2015.

7. Beer TM, Armstrong AJ, Rathkopf DE, Loriot Y, Sternberg CN, Higano CS, Iversen P, Bhattacharya S, Carles J, Chowdhury S, et al: Enzalutamide in metastatic prostate cancer before chemotherapy. N Engl J Med 371: 424-433, 2014.

8. Song C, Hu CD, Masago M, Kariyai K, Yamawaki-Kataoka Y, Shibatohge M, Wu D, Satoh T and Kataoka T: Regulation of a novel human phospholipase C, PLCepsilon, through membrane targeting by Ras. J Biol Chem 276: 2752-2757, 2001.

9. Bunney TD and Katan M: PLC regulation: Emerging pictures for molecular mechanisms. Trends Biochem Sci 36: 88-96, 2011.

10. Bai Y, Edamatsu H, Maeda S, Saito H, Suzuki N, Satoh T and Kataoka T: Crucial role of phospholipase Cepsilon in chemical carcinogen-induced skin tumor development. Cancer Res 64: 8808-8810, 2004.

11. Wang LD, Zhou FY, Li XM, Sun LD, Song X, Jin Y, Li JM, Kong GQ, Qi H, Cui J, et al: Genome-wide association study of esophageal squamous cell carcinoma in Chinese subjects identifies susceptibility loci at PLCE1 and C20 or f54. Nat Genet 42: 759-763, 2010.

12. Wang X, Fan Y, Du Z, Fan J, Hao Y, Wang J, Wu X and Luo C: Knockdown of phospholipase $\mathrm{C} \varepsilon$ (PLC $\varepsilon$ ) inhibits cell proliferation via phosphatase and tensin homolog deleted on chromosome 10 (PTEN)/AKT signaling pathway in human prostate cancer. Med Sci Monit 24: 254-263, 2018.

13. Wang Y, Wu X, Ou L, Yang X, Wang X, Tang M, Chen E and Luo C: PLCe knockdown inhibits prostate cancer cell proliferation via suppression of Notch signalling and nuclear translocation of the androgen receptor. Cancer Lett 362: 61-69, 2015.

14. Buonamici S, Williams J, Morrissey M, Wang A, Guo R, Vattay A, Hsiao K, Yuan J, Green J, Ospina B, et al: Interfering with resistance to smoothened antagonists by inhibition of the PI3K pathway in medulloblastoma. Sci Transl Med 2: 51ra70, 2010.

15. Wahid M, Jawed A, Mandal RK, Dar SA, Khan S, Akhter N and Haque S: Vismodegib, itraconazole and sonidegib as hedgehog pathway inhibitors and their relative competencies in the treatment of basal cell carcinomas. Crit Rev Oncol Hematol 98: 235-241, 2016.

16. Shigemura K, Huang WC, Li X, Zhau HE, Zhu G, Gotoh A, Fujisawa M, Xie J, Marshall FF and Chung LW: Active sonic hedgehog signaling between androgen independent human prostate cancer cells and normal/benign but not cancer-associated prostate stromal cells. Prostate 71: 1711-1722, 2011.

17. Yamamichi F, Shigemura K, Behnsawy HM, Meligy FY, Huang WC, Li X, Yamanaka K, Hanioka K, Miyake H, Tanaka K, et al: Sonic hedgehog and androgen signaling in tumor and stromal compartments drives epithelial-mesenchymal transition in prostate cancer. Scand J Urol 48: 523-532, 2014.

18. Behnsawy HM, Shigemura K, Meligy FY, Yamamichi F, Yamashita M, Haung WC, Li X, Miyake H, Tanaka K, Kawabata M, et al: Possible role of sonic hedgehog and epithelialmesenchymal transition in renal cell cancer progression. Korean J Urol 54: 547-554, 2013.

19. Lauth M, Bergstrom A, Shimokawa T and Toftgard R: Inhibition of GLI-mediated transcription and tumor cell growth by small-molecule antagonists. Proc Natl Acad Sci USA 104: 8455-8460, 2007.

20. Gonnissen A, Isebaert S and Haustermans K: Hedgehog signaling in prostate cancer and its therapeutic implication. Int J Mol Sci 14: 13979-14007, 2013.

21. Karhadkar SS, Bova GS, Abdallah N, Dhara S, Gardner D, Maitra A, Isaacs JT, Berman DM and Beachy PA: Hedgehog signalling in prostate regeneration, neoplasia and metastasis. Nature 431: 707-712, 2004.

22. Chen Y, Bieber MM and Teng NN: Hedgehog signaling regulates drug sensitivity by targeting $\mathrm{ABC}$ transporters $\mathrm{ABCB} 1$ and ABCG2 in epithelial ovarian cancer. Mol Carcinog 53: 625-634, 2014. 
23. Sims-Mourtada J, Izzo JG, Ajani J and Chao KS: Sonic Hedgehog promotes multiple drug resistance by regulation of drug transport. Oncogene 26: 5674-5679, 2007.

24. Singh S, Chitkara D, Mehrazin R, Behrman SW, Wake RW and Mahato RI: Chemoresistance in prostate cancer cells is regulated by miRNAs and Hedgehog pathway. PLoS One 7: e40021, 2012.

25. Chen M, Feuerstein MA, Levina E, Baghel PS, Carkner RD, Tanner MJ, Shtutman M, Vacherot F, Terry S, de la Taille A and Buttyan R: Hedgehog/Gli supports androgen signaling in androgen deprived and androgen independent prostate cancer cells. Mol Cancer 9: 89, 2010.

26. Chen G, Goto Y, Sakamoto R, Tanaka K, Matsubara E, Nakamura M, Zheng H, Lu J, Takayanagi R and Nomura M: GLI1, a crucial mediator of sonic hedgehog signaling in prostate cancer, functions as a negative modulator for androgen receptor. Biochem Biophys Res Commun 404: 809-815, 2011.

27. Du Z, Li L, Sun W, Wang X, Zhang Y, Chen Z, Yuan M, Quan Z, Liu N, Hao Y, et al: HepaCAM inhibits the malignant behavior of castration-resistant prostate cancer cells by downregulating Notch signaling and PF-3084014 (a gamma-secretase inhibitor) partly reverses the resistance of refractory prostate cancer to docetaxel and enzalutamide in vitro. Int J Oncol 53: 99-112, 2018

28. Livak KJ and Schmittgen TD: Analysis of relative gene expression data using real-time quantitative PCR and the 2(-Delta Delta C(T)) method. Methods 25: 402-408, 2001.

29. Gonnissen A, Isebaert S, McKee CM, Dok R, Haustermans K and Muschel R: The hedgehog inhibitor GANT61 sensitizes prostate cancer cells to ionizing radiation both in vitro and in vivo. Oncotarget 7: 84286-84298, 2016.

30. Chen Q, Xu R, Zeng C, Lu Q, Huang D, Shi C, Zhang W, Deng L, Yan R, Rao H, et al: Down-regulation of Gli transcription factor leads to the inhibition of migration and invasion of ovarian cancer cells via integrin $\beta 4$-mediated FAK signaling. PLoS One 9: e88386, 2014.

31. Guerrero J, Alfaro IE, Gomez F, Protter AA and Bernales S: Enzalutamide, an androgen receptor signaling inhibitor, induces tumor regression in a mouse model of castration-resistant prostate cancer. Prostate 73: 1291-1305, 2013.

32. Hicks SN, Jezyk MR, Gershburg S, Seifert JP, Harden TK and Sondek J: General and versatile autoinhibition of PLC isozymes. Mol Cell 31: 383-394, 2008.

33. Wing MR, Snyder JT, Sondek J and Harden TK: Direct activation of phospholipase C-epsilon by Rho. J Biol Chem 278 . 41253-41258, 2003

34. Luo XP: Phospholipase C epsilon-1 inhibits p53 expression in lung cancer. Cell Biochem Funct 32: 294-298, 2014.
35. Abnet CC, Freedman ND, Hu N, Wang Z, Yu K, Shu XO, Yuan JM, Zheng W, Dawsey SM, Dong LM, et al: A shared susceptibility locus in PLCE1 at 10q23 for gastric adenocarcinoma and esophageal squamous cell carcinoma. Nat Genet 42 : 764-767, 2010.

36. Smrcka AV, Brown JH and Holz GG: Role of phospholipase $\mathrm{C} \varepsilon$ in physiological phosphoinositide signaling networks. Cell Signal 24: 1333-1343, 2012

37. Du HF, Ou LP, Song XD, Fan YR, Yang X, Tan B, Quan Z, Luo CL and Wu XH: Nuclear factor-kappa B signaling pathway is involved in phospholipase Cepsilon-regulated proliferation in human renal cell carcinoma cells. Mol Cell Biochem 389: 265-275, 2014

38. Yang X, Ou L, Tang M, Wang Y, Wang X, Chen E, Diao J, Wu X and Luo C: Knockdown of PLCepsilon inhibits inflammatory cytokine release via STAT3 phosphorylation in human bladder cancer cells. Tumour Biol 36: 9723-9732, 2015.

39. Sharp A, Welti J, Blagg J and de Bono JS: Targeting androgen receptor aberrations in castration-resistant prostate cancer. Clin Cancer Res 22: 4280-4282, 2016.

40. Ardiani A, Gameiro SR, Kwilas AR, Donahue RN and Hodge JW: Androgen deprivation therapy sensitizes prostate cancer cells to T-cell killing through androgen receptor dependent modulation of the apoptotic pathway. Oncotarget 5: 9335-9348, 2014.

41. Tran C, Ouk S, Clegg NJ, Chen Y, Watson PA, Arora V, Wongvipat J, Smith-Jones PM, Yoo D, Kwon A, et al: Development of a second-generation antiandrogen for treatment of advanced prostate cancer. Science 324: 787-790, 2009.

42. Gonnissen A, Isebaert S and Haustermans K: Targeting the Hedgehog signaling pathway in cancer: Beyond smoothened. Oncotarget 6: 13899-13913, 2015.

43. Tang X, Deng L, Chen Q, Wang, Y, Xu R, Shi C, Shao J, Hu G, Gao M, Rao H, et al: Inhibition of Hedgehog signaling pathway impedes cancer cell proliferation by promotion of autophagy. Eur J Cell Biol 94: 223-233, 2015.

44. Nguyen HG, Yang JC, Kung HJ, Shi XB, Tilki D, Lara PN Jr, DeVere White RW, Gao AC and Evans CP: Targeting autophagy overcomes enzalutamide resistance in castration-resistant prostate cancer cells and improves therapeutic response in a xenograft model. Oncogene 33: 4521-4530, 2014.

This work is licensed under a Creative Commons Attribution-NonCommercial-NoDerivatives 4.0 International (CC BY-NC-ND 4.0) License. 